\title{
Clinical Trials of Thermosensitive Nanomaterials: An Overview
}

\author{
Stefania Nardecchia ${ }^{1,2}{ }^{(D)}$, Paola Sánchez-Moreno ${ }^{3}\left(\mathbb{D}\right.$, Juan de Vicente ${ }^{1,2}(\mathbb{D}$, \\ Juan A. Marchal $2,4,5,6$ (D) and Houria Boulaiz $2,4,5,6, *$ (D) \\ 1 Department of Applied Physics, Faculty of Sciences, University of Granada, C/Fuentenueva s/n, \\ 18071 Granada, Spain; stefania@ugr.es (S.N.); jvicente@ugr.es (J.d.V.) \\ 2 Excellence Research Unit “Modeling Nature” (MNat), University of Granada, 18016 Granada, Spain; \\ jmarchal@ugr.es \\ 3 Nanobiointeractions \& Nanodiagnostics, Istituto Italiano di Tecnologia, Via Morego, 30, 16163 Genova, Italy; \\ paola.sanchez@iit.it \\ 4 Department of Human Anatomy and Embryology, University of Granada, 18016 Granada, Spain \\ 5 Biopathology and Medicine Regenerative Institute (IBIMER), University of Granada, 18016 Granada, Spain \\ 6 Biosanitary Institute of Granada (ibs.GRANADA), SAS-Universidad de Granada, 18016 Granada, Spain \\ * Correspondence: hboulaiz@ugr.es; Tel.: +34-958-241-271
}

Received: 30 November 2018; Accepted: 30 January 2019; Published: 2 February 2019

\begin{abstract}
Currently, we are facing increasing demand to develop efficient systems for the detection and treatment of diseases that can realistically improve distinct aspects of healthcare in our society. Sensitive nanomaterials that respond to environmental stimuli can play an important role in this task. In this manuscript, we review the clinical trials carried out to date on thermosensitive nanomaterials, including all those clinical trials in hybrid nanomaterials that respond to other stimuli (e.g., magnetic, infrared radiation, and ultrasound). Specifically, we discuss their use in diagnosis and treatment of different diseases. At present, none of the existing trials focused on diagnosis take advantage of the thermosensitive characteristics of these nanoparticles. Indeed, almost all clinical trials consulted explore the use of Ferumoxytol as a current imaging test enhancer. However, the thermal property is being further exploited in the field of disease treatment, especially for the delivery of antitumor drugs. In this regard, ThermoDox ${ }^{\circledR}$, based on lysolipid thermally sensitive liposome technology to encapsulate doxorubicin (DOX), is the flagship drug. In this review, we have evidenced the discrepancy existing between the number of published papers in thermosensitive nanomaterials and their clinical use, which could be due to the relative novelty of this area of research; more time is needed to validate it through clinical trials. We have no doubt that in the coming years there will be an explosion of clinical trials related to thermosensitive nanomaterials that will surely help to improve current treatments and, above all, will impact on patients' quality of life and life expectancy.
\end{abstract}

Keywords: thermosensitive nanomaterials; USPIO; magnetic nanoparticles; Ferumoxytol; gold nanoparticles; ThermoDox

\section{Introduction}

Nowadays, there is a real need to seek out more efficient systems for the diagnosis and treatment of many diseases and hence achieve better overall health in our society. Sensitive nanomaterials that can respond to exact stimuli are part of an important strategy in many biomedical fields like drug delivery, biosensing, and biomaterials [1,2] These materials can be functionalized to respond to temperature, $\mathrm{pH}$, light, electric field, magnetic field, radiofrequency and ultrasound, amongst many others [3,4]. Specifically, thermosensitive nanomaterials are promising in disease treatment and 
diagnosis due to their capacity to aim at pre-selected sites when simulated in a certain temperature range [5]. Amid disparities of diversified biomedical applications, thermosensitive nanomaterials have remarkable features, which make them strong candidates for use in medical applications such as drug delivery, diagnostic devices, and thermal therapy.

The field of thermal therapy has grown exponentially in recent years. Indeed, several studies have been registered using traditional hyperthermia, in combination with chemotherapy and/or radiation therapy, for the elimination of many types of tumors [6-8]. In magnetic hyperthermia, which has reduced side effects, tumor cells receive heat through the use of magnetic nanoparticles (MNPs) and an alternating magnetic field (AMF) [9]. AMF heating promotes deep tumor penetration and temperature regulation [10]. MNP-based thermal therapy has remarkable advantages over traditional thermal therapies such as (i) innocuous penetration of frequencies produced by MNPs, (ii) homogenous heat generation, (iii) the possibility of inducing antitumoral immunity, and (iv) the development of a multi-modality device providing thermal therapy and magnetic resonance imaging (MRI) [11]. Among different clinical therapies, magnetic fluid hyperthermia (MFH)-based thermotherapy has received great interest as an antitumor strategy, wherein ultrasmall superparamagnetic iron oxide nanoparticles (USPIOs) are principally used to induce localized therapeutic heat (reaching $42-45{ }^{\circ} \mathrm{C}$ ) inside the tumors [12]. Also, the heat generated from specific nanoparticles (i.e., gold nanoparticles (GNPs)) can be utilized to eradicate/damage cancerous cells by photothermal therapy (PTT) [13]. When a laser is focused on a tissue, the photons are absorbed by the cellular and intercellular areas and their energies are converted into heat, inducing cellular death. Unlike traditional hyperthermia, PTT is produced in the area directly surrounding nanoparticles, and local temperatures can rise, in very short time scales, by tens or hundreds of degrees Celsius above physiological temperature. This would help to reduce the side effects of the antitumor treatments because the treatment can be directed to the targeted tissue.

Controlling the application of thermal energy to living tissues is a great challenge, which is driving the development of many devices and treatment techniques, both at preclinical and clinical levels [14]. The trend is to improve non-invasive monitoring methods in contrast to existing techniques, such as tissue biopsies, that are based on destructive/invasive methods.

Non-invasive procedures like positron emission tomography (PET) and MRI lack the specificity to be a feasible alternative to cell tracing. Single photon emission computed tomography, even though it permits non-invasive tracking of in vivo bio-dissemination of radiotracers at picomolar concentrations, has several disadvantages (e.g., limited spatial resolution, lack of anatomical details for reference, etc.) that make it difficult to target the exact location of lesions. The combination of different imaging modalities using multimodal probes can be of great interest in molecular imaging [15]. This synergistic combination provides improved visualization of biological targets, and obtains information on all aspects of cell or tissue structure and function, which is hard to obtain by a single imaging modality [16].

New devices based on thermal nanoparticles combined with multi-modality imaging would simplify non-invasive monitoring of treatments, since they could allow simultaneous dynamic imaging of both structure and function and directly provide valuable information on pharmacokinetics and drug metabolism. Moreover, nanomaterials can provide information on the biological state of cells in addition to their physical location [17].

Until now, many types of nanomaterials have been used to build thermosensitive nanosystems for therapy and diagnosis, such as inorganic nanoparticles, carbonaceous materials, and liposomal formulations $[5,18,19]$.

\subsection{Inorganic Nanoparticles}

Among the extensive variety of inorganic nanoparticles reported in the literature, MNPs, USPIOs, and GNPs experience increased relevance as thermosensitive nanomaterials for biomedicine [20,21].

MNPs are known to be very promising for biomedical treatments [22]. In particular, iron oxide nanoparticles (IONs) possess an inherit elemental composition that makes them biocompatible and 
degradable by nature [23]. IONs can be produced in very small sizes $(<40 \mathrm{~nm})$, with uniform size distribution, superparamagnetic nature, possibility of functionalization with different molecules (drug molecules, fluorescent compounds [24-26]), solubility in water along with a high magnetic moment. These are simply some of the characteristics that make these materials attractive for many applications, e.g., hyperthermia and magnetic resonance enhancement. The combination of magnetic and other properties in one single nanoparticle can create a path to new multifunctional nanomaterials that display multimodal properties $[27,28]$. For example, externally applied magnetic fields can be used to address some specific targeted functionalization such as the controlled release of drugs in desired areas, gathering the nanocomposites in a specific region for diagnosis or treatment and, finally, eradicating them at the end of the whole procedure [29,30]. It is also important to point out that multimodal MNPs can also open the access to the monitoring of all the possible steps included in the treatments by taking advantage of numerous imaging procedures like MRI and computed tomography (CT) [31,32].

Among the various MNPs, the USPIOs are very useful for biomedical applications [33,34]. The USPIOs are magnetite $\left(\mathrm{Fe}_{3} \mathrm{O}_{4}\right)$ and / or maghemite $\left(\gamma-\mathrm{Fe}_{2} \mathrm{O}_{3}\right)$ particles, usually coated with different surface coating molecules, such as citrate, polymers, and silica. This hydrophilic coating helps the water dispersibility and improves the colloidal stability and biocompatibility of the USPIOs $[35,36]$.

In the family of nanoparticles, GNPs are unlike any others, displaying some unique optical properties, where the origin is due to an electromagnetic phenomenon called surface plasmon resonance (SPR) [37]. SPR depends on several characteristics of GNPs like, for example, their size, composition, shape, etc. [38]. The control of SPR effect on GNPs has been shown to lead to important bioimaging applications and/or photothermal agents [39,40]. Last but not least, there is another quite interesting property of GNPs, which is the heat generation after absorbing infrared light. After excitation by the light source, the nanoparticles face the possibility to dissipate the heat into their surroundings, melt, or even cause structural damage. This unique property has been exploited for PTT applications [41,42].

\subsection{Carbon-Based Nanomaterials}

Other types of inorganic materials actively investigated in biomedical applications are carbon-based nanomaterials (CBNs) [43]. One popular two-dimensional (2D) CBN is a derivative of graphite, termed graphene, a single layer of $\mathrm{sp}^{2}$-bonded carbon atoms. The main characteristics of these materials are high mechanical strength and excellent thermal and electrical conductivity. Graphene in its oxidized form, graphene oxide (GO), exhibits oxygen atoms on the edges and basal planes of its structure. The functional groups with oxygen atoms (epoxy, hydroxyl, carboxylic and carbonyl, etc.) turn out to be ideal binding sites for different molecules, such as polymers and biological molecules [44], and increases its hydrophilicity in comparison to graphene. It has been reported that $\mathrm{GO}$ is also non-toxic and biocompatible at low concentrations [45]. Another interesting feature is a high photothermal conversion capability in the near-infrared (NIR) wavelength region. Thus, the combination of strong absorption and heat transfer can be used to kill tumor cells directly [46]. In addition, incorporating GO nanosheets into thermosensitive hydrogels may reveal some novel and interesting applications. The main advantage of a thermosensitive hydrogel is that it is a viscous liquid at low temperature, which allows easy handling, incorporation of cells or biomolecules, and finally injection in a minimally invasive manner. Importantly, shape stability at the injection site is warranted by their gelation at body temperature. Incorporating CBNs improves their fracture strength and, in some cases, the elastic modulus as well, which is a requirement for load-bearing applications. The kinetics of the temperature response can be tuned by the quality and quantity of the filler, thereby broadening their possible applications as sensors and drug delivery systems.

\subsection{Liposomal Formulations}

In addition to inorganic materials, thermosensitive liposomes (TSLs) are also interesting instruments for drug delivery [24,47]. Liposomes are spherical vesicles composed of a membrane 
bilayer, usually constituted of phospholipids and an aqueous core [48]. Conventional liposomes are approved for use as delivery systems for clinical use in oncology [49]. However, the liposomes present poor penetration and a limited drug release factor in the tumor area. Otherwise, upon administration, circulating TSLs are activated locally under conditions of mild hyperthermia by increasing the temperature (to $40-41{ }^{\circ} \mathrm{C}$ ) using an external heat source [50]. The increase of the temperature causes compositional changes in the liposomal membrane, creating openings that permit the release of the encapsulated drug. These thermo-devices favor the specific release of the largest amount of cytotoxic agent to a heat-treated tumor site, limiting the injury to the surrounding normal tissue [51]. To overcome these limitations, TSLs have been developed as new controlled drug release systems [52]. ThermoDox ${ }^{\circledR}$, a TSL containing DOX, is the only TSL formulation to arrive at drug development. In the few last years, research has focused on solving the limitations associated with the ThermoDox®formulation, such as poor circulation lifetime or the membrane permeability of DOX for different diseases [53]. In this regard, Lindner et al. developed new TSLs with prolonged liposome circulation time for mild hyperthermia, and showed an increased plasma half-life for the loaded drug with $t_{1 / 2}=9.6 \mathrm{~h}$ in hamsters and $t_{1 / 2}=5.0 \mathrm{~h}$ in rats dependent on changes in composition of TSLs [54]. Limmer et al. showed an increase in plasma half-life of 0.53 to $2.59 \mathrm{~h}$ for gemcitabine (GEM) when the size of TSLs was increased [55]. Furthermore, the development of TSLs loaded with non-membrane permeable drugs (e.g., cisplatin (HTLC) [56], GEM, oxaliplatin [57]) allows their use for different diseases that cannot be treated with DOX (e.g., breast, ovarian, cervical, gastric cancers). Moreover, new applications of the liposomal formulations will open new biomedical possibilities. [58,59]. For example, the synergy of TSLs and magnetic resonance-guided drug delivery will open the possibility to target desired injured sites and online monitoring at the same time [60,61]. This is just one example of the extraordinary true theranostic nature of thermosensitive liposomes, that is the ability to combine specific targeted therapy based on specific targeted diagnosis. In this regard, Rizzitelli et al. [62] published a preclinical study describing a novel protocol for the DOX release from TSLs monitored by MRI in a breast cancer mouse model. In addition, DI-TSLs (DOX and indocyanine green (ICG) loaded TSLs) capable of responding to NIR were manufactured. This theranostic system allows the control of the release of drugs from TSLs (PTT for hyperthermia drug release) and uses fluorescence of the same ICG to continuously monitor the drug-release, biodistribution and antitumor efficacy of the DI-TSL system in the body [63]. Recently, a microfluidic chip has been developed capable of adjusting the temperature rise for the drug control release by TSL. This system allows procedures such as cytometric analysis and AFM scanning, as well as presenting small size, biocompatibility and low cost [64]. Table 1 lists some of the recent publications related to the development of new TSLs formulations and new applications.

Next, we will focus on a review of the clinical trials carried out to date with thermosensitive nanomaterials including all those clinical trials in which the nanomaterials of interest are hybrid and also respond to other stimuli (e.g., magnetic, infrared radiation and ultrasound). Specifically, we discuss their use in both diagnosis and treatment of different diseases without forgetting those already approved by Food and Drug Administration (FDA) for clinical use (Figure 1). 
Table 1. New TSLs systems developed for cancer treatment and diagnosis.

\begin{tabular}{|c|c|c|c|c|}
\hline Type of TSLs & Drug & Improvement & Use & Ref. \\
\hline $\begin{array}{c}\text { Liposome formulations of } \\
\text { HTLC }\end{array}$ & HTLC & $\begin{array}{c}\text { Treatment of cervical } \\
\text { carcinoma }\end{array}$ & Treatment & [56] \\
\hline $\begin{array}{c}\text { Liposomal formulations with } \\
\text { drug }\end{array}$ & $\begin{array}{l}\text { GEM } \\
\text { DOX }\end{array}$ & $\begin{array}{l}\text { Increased drug } \\
\text { plasma half-life }\end{array}$ & Treatment & $\begin{array}{l}{[55]} \\
{[65]}\end{array}$ \\
\hline $\begin{array}{l}\text { Multi-modal thermo-sensitive } \\
\text { polymer-modified liposomes } \\
\text { (MTPLs) }\end{array}$ & $\begin{array}{l}\text { MnSO4, } \\
\text { rhodamine, DOX }\end{array}$ & $\begin{array}{l}\text { Monitor drug delivery in } \\
\text { cancer therapy }\end{array}$ & Diagnosis & [66] \\
\hline Liposomal ICG & ICG & $\begin{array}{c}\text { Deliver ICG as the NIR in the } \\
\text { treatment of triple negative } \\
\text { breast cancer }\end{array}$ & Treatment & [67] \\
\hline $\begin{array}{l}\text { TSLs loaded with drug and } \\
\text { fullerene decorated with IONs }\end{array}$ & ICG, DOX & $\begin{array}{l}\text { Multifunctional TSLs showing } \\
\text { radiofrequency release and } \\
\text { MRI for tumor therapy }\end{array}$ & $\begin{array}{l}\text { Diagnosis } \\
\text { and treatment }\end{array}$ & [60] \\
\hline $\begin{array}{l}\text { TSLs loaded with drugs and } \\
\text { mesoporous silica } \\
\text { nanoparticles }\end{array}$ & ICG, DOX & $\begin{array}{l}\text { Multifunctional nanoplatform } \\
\text { for integrate diagnosis and } \\
\text { treatment (photodynamic } \\
\text { therapy and PTT) for cancer }\end{array}$ & $\begin{array}{l}\text { Diagnosis } \\
\text { and treatment }\end{array}$ & [68] \\
\hline
\end{tabular}

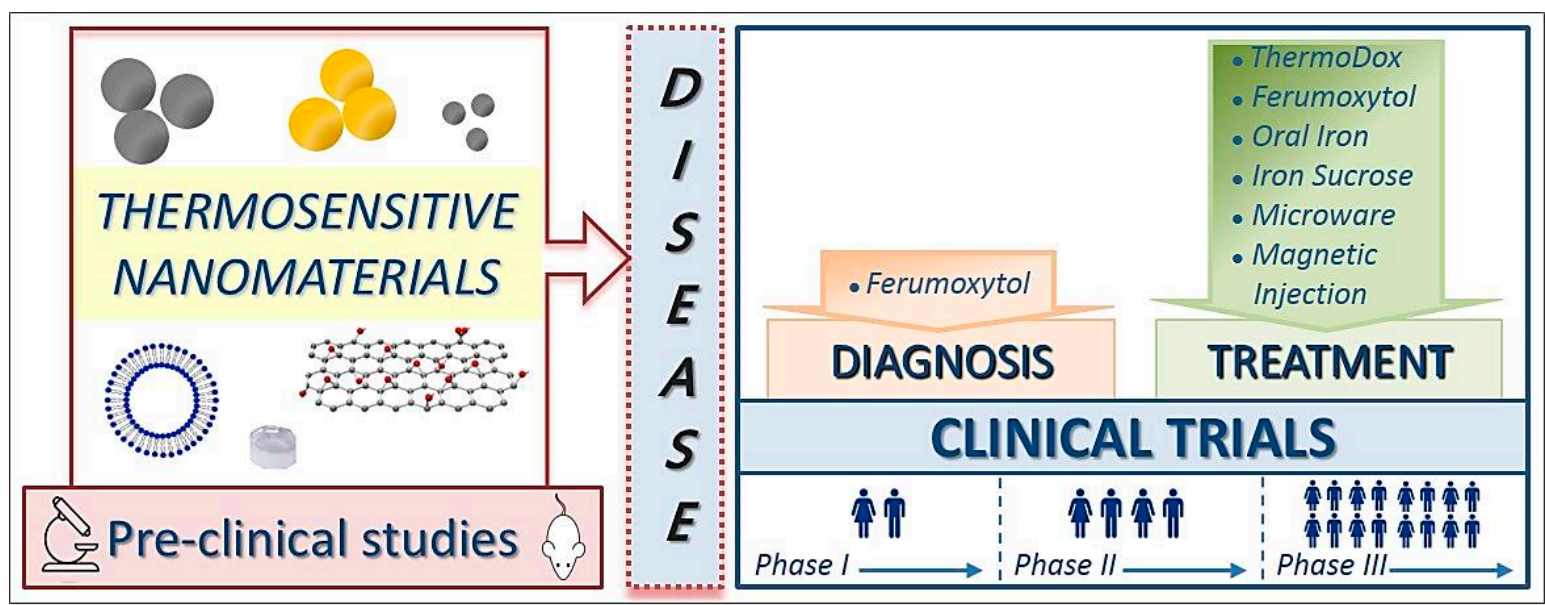

Figure 1. Illustration of the uses of thermosensitive nanomaterials.

\section{Clinical Trials and Marketed Thermosensitive Nanomedicines}

Several clinical trials are currently being conducted or have been completed in a wide spectrum of pathologies (https://clinicaltrials.gov/). Its use is focused on both treatment and diagnosis of different diseases and some of them have been approved by regulatory bodies. We have used the terms "Thermosensitive", "USPIO", "Magnetic nanoparticles", "Ferumoxytol", "gold nanoparticles" or "ThermoDox" as keywords when looking for this information. When conducting our search, we have observed that a discrepancy exists between the number of published papers in thermosensitive nanomaterials and the number of nanomaterials in clinical use (Figure 2). 

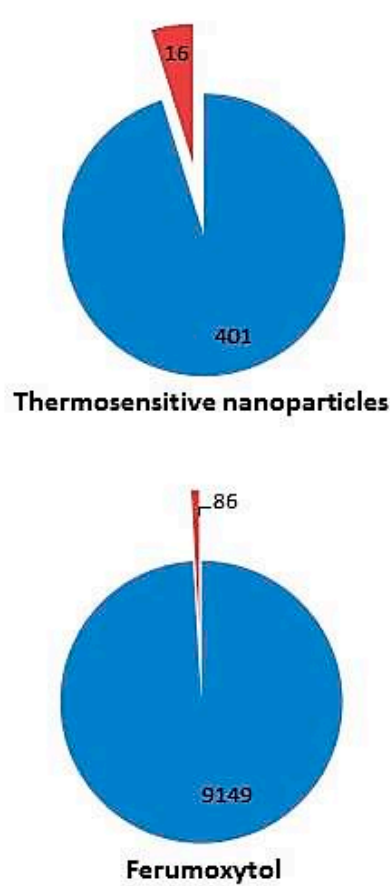

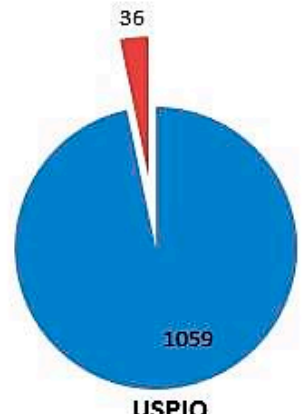

12

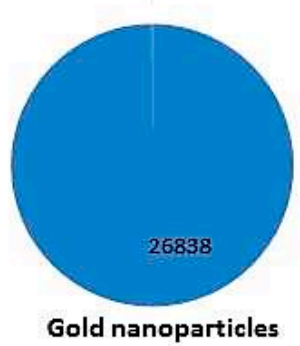

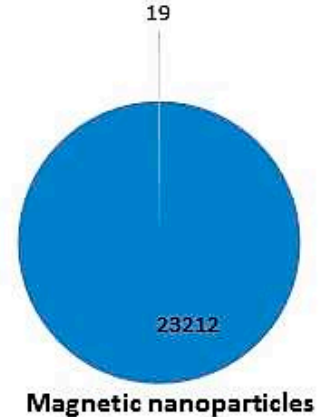

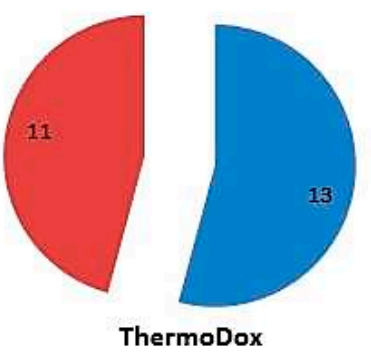

Figure 2. Number of publications (blue) versus clinical trials (red) related to thermosensitive nanomaterials, USPIOs, MNPs, GNPs, Ferumoxytol and ThermoDox®. Data reported here reflect manuscripts available through PubMed database and clinicaltrials.gov up to November 2018.

\subsection{Thermosensitive Nanomaterials for Disease Diagnosis}

Until now, the thermosensitive nanomaterials used in the diagnosis of different pathologies do not take advantage of the thermal characteristics of these materials. Indeed, among all thermosensitive nanoparticles, the majority of clinical trials have been registered with USPIOs as contrast agents and only one clinical trial uses MNPs to separate mature sperm from immature ones. However, clinical trials have begun to be recorded in order to investigate the safety of novel nanoparticles such as carbon black and graphene nanoparticles [69] (Table 2).

\subsubsection{Ferumoxytol as a Current Imaging Test Enhancer}

USPIOs attracted extensive research efforts for cellular imaging applications and their clinical research has been recently updated by Wang and Idee [70]. Ferumoxytol, an USPIO system developed as an MRI contrast agent in 2000, is better known as a therapeutic agent for the treatment of iron deficiency anemia (IDA) in the setting of chronic kidney disease (CKD). Nevertheless, in recent years, ferumoxytol has regained interest as an agent for MRI enhancement and most of the clinical trials carried out on nanothermal materials focus on their use in the diagnosis of several pathologies. Ferumoxytol, has many characteristics that make it an attractive candidate to be a good contrast agent for vascular and perfusion-weighted MRI (i) easy administration through a rapid bolus, (ii) long intravascular half-life (14-15 h), (iii) less limited by idiosyncratic and allergic reactions in comparison to other USPIOs; (iv) provides a strong T1- and T2-signal on MRI and is taken up by cells in bone marrow. Moreover, ferumoxytol is an iron-based agent that can be an alternative to gadolinium-based contrast agents (GBCAs) in patients with compromised renal function since it does not cause nephrogenic systemic fibrosis [71]. It has been shown that ferumoxytol is finally taken up by macrophages/the reticuloendothelial system in the spleen, liver, and lymph nodes. This uptake mechanism is being used as a novel imaging technique for tumors, vascular lesions, and lymph nodes. Currently, many clinical trials are being conducted to determine its efficacy and safety as an intravenous contrast agent in MRI. 


\section{a. Cancer Diagnosis}

In the field of oncology, there are currently several investigations that aim to use ferumoxytol-enhanced MRI to diagnose primary and metastatic tumors. USPIOs do not directly identify the tumoral cells, they help to improve the resolution of the MRI image, which makes it easier to make a differential diagnosis that indirectly, and together with the results obtained through other tests such as steady-state blood volume mapping, indicates the state of the lesion. Although visualization of the lesion with USPIOs is generally similar to GBCAs, differences in improvement patterns, based on the breakdown of the blood-brain barrier marker, can help the differential diagnosis [72]. Parenchymal improvement is best seen in the delayed phase, $24 \mathrm{~h}$ after the injection of USPIOs as the extravasation of large molecules is slow. USPIOs improve the delimitation of the edges and allows the evaluation of the internal morphology of the lesion as it has been reflected in several MRI sequences weighted in T1 used clinically. The decrease in the signal in the T2-weighted images in the delayed phase can indicate great local USPIO levels or retention in tumor-associated macrophages. The low T1 and T2 improvement together can help differentiate tumor necrosis (extracellular iron) from solid tumor (intracellular iron). Perfusion MRI and steady-state blood volume mapping can also enhance tumor classification by recognizing the most malignant area for surgical selection and monitoring of therapy [73]. There are currently several clinical trials that aim to use ferumoxytol-enhanced MRI to diagnose primary and metastatic tumors. This is the case with the phase II trial study that will analyze the effectiveness of ferumoxytol, in comparison to gadolinium, in measuring tumors in patients undergoing treatment for brain tumors or other tumors that have metastasized to the brain [74]. In addition, another clinical trial is underway to determine by MRI if ferumoxytol can provide more data to understand the spread of head and neck squamous cell carcinoma and melanoma [75], breast cancer, and prostate cancer [76].

Moreover, another clinical trial focuses on the analysis of how well ferumoxytol-enhanced MRI works in imaging lymph node metastases in patients with different types of cancers such as esophageal cancer [77], advanced rectal cancer [77,78], prostate [79], bladder, and kidney cancers [80], breast cancer [81], and brain neoplasm in both adults and children [82-85].

In addition, ferumoxytol-enhanced MRI can serve not only in the detection of cancer cells but also in the differentiation between malign and infectious diseases. In fact, Macrophages play an important role in the pathogenesis of inflammation. After human intravenous (IV) injection, superparamagnetic iron oxide nanoparticles (SPIOs) arrive at inflammation sites where their small size of (10-30 nm) enables them to leak through permeable capillaries (5-100 nm) into inflamed tissues. Then they are phagocytosed by macrophages displaying prolonged T2 and T2* effects on contrast-enhanced MR images in macrophage-infiltrated tissues [73]. Seyfer et al. [86] found that abscesses (infectious masses) could be differentiated from viable tumor because they displayed a smaller contrast-to-noise ratio than neoplasia when imaged using a T2*-weighted MRI sequence with SPIOs. Twenty-four hours after the USPIO-injection, no changes were observed in VX2 carcinomas, whereas a mean reduction of the contrast-to-noise ratio (CNR) of approximately $90 \%$ was noticed in abscesses. In addition to that, necrotic tumors can also be differentiated from viable tumors and from abscesses as they present mixed behavior after USPIO injection. On histopathologic examination, abscess and necrotic parts of the tumor were found to include iron-containing monocytes demonstrating that the reduction in CNR was caused by USPIO-tagged monocytes. In this context, researchers from Stanford University School of Medicine conducted a pilot trial to analyze whether ferumoxytol-enhanced MRI can be used in the differentiation between bone sarcomas and osteomyelitis [87]. Furthermore, ferumoxytol-enhanced MRI can serve also to assess response to therapy since it has been seen that after treatment of brain tumor with chemoradiotherapy or radiation, augmented edema and contrast improvement on MRI may either represent (i) tumor progression since the increase of the tumor mass indicates the failure of the ongoing treatment, or (ii) pseudoprogression, which results in a subacute inflammatory reaction caused by the treatment without underlying tumor [88]. Being able to differentiate between these two procedures is a key element for patient survival. In this sense, some pilot trials study the effectiveness of ferumoxytol-MRI in assessing response to pembrolizumab in patients with tumors on the brain 
originating from melanoma and glioblastoma metastasis [89], in patients with glioblastoma multiforme receiving temozolomide and radiation therapy [90] and in patients with high grade glioma treated with a bevacizumab and dexamethasone [91]. Diagnostic procedures, such as ferumoxytol MRI, may help measure a patient's response to antitumor drug treatment.

b. Non-tumor Pathology Diagnosis

Furthermore, ferumoxytol is also being studied for its applicability as a contrast agent for MRI of non-tumor pathologies such as myocardial Infarction [92], Hereditary Hemorrhagic Telangiectasia [93], Type 1A diabetes [94,95], Renal Transplant Rejection [96] and Osteonecrosis [97]. A randomized phase II trial studies how well gadolinium and ferumoxytol MRI works in diagnosing patients with abnormalities in the Central Nervous System (CNS) [98]. Determining the extent of inflammation associated with pathologies in the CNS may be useful both for diagnosis, prognosis, and monitoring the treatment response of current and future immunotherapies. In this sense, researchers investigate the safety of ferumoxytol as a contrast agent to be used in the identification of neuroinflammation in multiple sclerosis (MS) patients [99]. For that, they want to (i) investigate its safety as determined by a lack of long-term signal change in healthy volunteers (HV) and people with MS; (ii) investigate if this drug improvement can be detected in MS lesions on 7-tesla (T) MRI; and (iii) analyze the special and temporal enhancement patterns of ferumoxytol compared to gadolinium contrast and gradient-echo imaging in MS lesions. A similar trial was carried out on human patients with epilepsy [100].

Human Immunodeficiency Virus (HIV)-associated neurocognitive disorders (HAND) have a significant impact on morbidity and quality of life of patients. HAND remains a chronic issue despite effective combination antiretroviral therapy. It is believed that Monocytes/macrophages play a critical role in the pathogenesis of this pathology. Neuroimaging HIV research has not focused on assessing Monocytes/macrophages-mediated inflammation in the brain. Hence, clinical trials are being conducted to find out if ferumoxytol-based imaging can identify ongoing inflammation due to perivascular monocytes/macrophages, which are thought to represent a key pathological correlate of HAND [101,102].

On the other hand, ferumoxytol can be used to enhance Magnetic Resonance Angiography (MRA). Conventional vascular imaging techniques are frequently contraindicated in patients with CKD due to their relative invasiveness and risk. Computed tomography angiography (CTA) requires nephrotoxic iodinated contrast and radiation that can cause a deterioration of renal function and even cause the need for a dialysis. GBCAs for MRA have been related with rare nephrogenic systemic fibrosis disease. Alternative methods of imaging also have drawbacks such as (i) increased risk of complications from conventional invasive catheter angiography, (ii) MRA without contrast permits visualization of smaller arteries but is less precise for larger vascular structures and (iii) ultrasound is frequently not suitable for evaluation of the deep vessels of the abdomen and pelvis. In this sense, a ferumoxytol-enhanced MRA phase 4 clinical trial is being undertaken [103]. Other clinical trials for coronary artery disease, peripheral arterial disease [104] and cerebrovascular disorders [105] are being carried out.

\subsubsection{Magnetic Nanoparticles for Sperm Sorting}

MNPs are also used in the field of fertility. In fact, a recent clinical trial was initiated in September 2018 and aims to achieve sperm separation by MNPs for Intracytoplasmic sperm microinjection (ICSI) cycles with teratozoospermia and women of over 35 years of age [106]. Women over 35 years old are likely to suffer from impaired oocyte repair capacity. Teratozoospermia is a condition that reflects morphological affection of sperm. These spermatozoa would add an extra burden to the oocyte after ICSI. The hypothesis of this research is whether the selection of mature sperm by a MNPs protocol would provide a more competent sperm to a likely affected oocyte that would improve the ICSI results. 
Table 2. Current clinical trials of thermosensitive nanomaterials for diagnosis of various diseases available on clinicaltrials.gov up to November 2018.

\begin{tabular}{|c|c|c|c|c|c|}
\hline Pathology & Interventions & ClinicalTrials ID & Phase & Date (First-Last Posted) & Ref. \\
\hline $\begin{array}{l}\text { Blood Biomarkers Vasodilation Blood } \\
\text { Clotting Lung Function Healthy Volunteers }\end{array}$ & $\begin{array}{l}\text { - Diesel exhaust particulate } \\
\text { - Carbon nanoparticles } \\
\text { - Small graphene oxide } \\
\text { - Ultrasmall graphene oxide }\end{array}$ & NCT03659864 & Not applicable & $\begin{array}{l}\text { September 2018-still } \\
\text { active }\end{array}$ & [69] \\
\hline Metastatic and Primary Brain Neoplasm & $\begin{array}{l}\text { - Ferumoxytol } \\
\text { - } 3 \text { Tesla MRI } \\
\text { - Dynamic Contrast-Enhanced MRI }\end{array}$ & NCT00659126 & Phase 2 & 2018-still active & [74] \\
\hline Head and Neck Cancer & $\begin{array}{l}\text { - Ferumoxytol } \\
\text { - MRI }\end{array}$ & NCT01895829 & Early Phase & 2013-still active & [75] \\
\hline $\begin{array}{l}\text { Solid Tumors } \\
\text { ER/PR Positive Breast Cancer } \\
\text { Active Brain Metastasis }\end{array}$ & Ferumoxytol followed by MM-398 & NCT01770353 & Phase 1 & 2013-still active & [76] \\
\hline $\begin{array}{l}\text { Rectal Cancer (Stage III) } \\
\text { Esophageal Cancer (Stage II-III) }\end{array}$ & $\begin{array}{l}\text { - Ferumoxytol } \\
\text { - MRI } \\
\text { - PET/CT }\end{array}$ & NCT03280277 & Phase 2 & 2017-still active & [77] \\
\hline Cancer of Lymph Node & $\begin{array}{l}\text { - Feraheme } \\
\text { - MRI }\end{array}$ & NCT01815333 & Not applicable & 2013-still active & [78] \\
\hline Prostate Cancer & Drug: Ferumoxytol & NCT01296139 & Phase 1 & 2011-2018 & [79] \\
\hline $\begin{array}{l}\text { Prostate Cancer } \\
\text { Bladder Cancer } \\
\text { Kidney Cancer }\end{array}$ & $\begin{array}{l}\text { - Ferumoxytol } \\
\text { - MRI }\end{array}$ & NCT02141490 & Phase 2 & 2014-still active & [80] \\
\hline $\begin{array}{l}\text { Breast Cancer } \\
\text { Prostate Cancer }\end{array}$ & $\begin{array}{l}\text { - Ferumoxytol } \\
\text { - MRI }\end{array}$ & NCT00087347 & Not applicable & 2013-still active & [81] \\
\hline $\begin{array}{l}\text { Soft Tissue Sarcoma } \\
\text { Childhood Brain Neoplasm }\end{array}$ & $\begin{array}{l}\text { - Ferumoxytol } \\
\text { - MRI }\end{array}$ & NCT00978562 & Not applicable & 2017-still active & [82] \\
\hline $\begin{array}{l}\text { Brain Injury } \\
\text { CNS: Degenerative and Infectious Disorder }\end{array}$ & $\begin{array}{l}\text { - Ferumoxytol } \\
\text { - MRI }\end{array}$ & NCT02452216 & Early Phase 1 & 2015-2017 & [83] \\
\hline Childhood Brain Neoplasm & $\begin{array}{l}\text { - Ferumoxytol } \\
\text { - MRI }\end{array}$ & NCT03179449 & Early Phase 1 & 2017-still active & [84] \\
\hline $\begin{array}{l}\text { CNS } \\
\text { Brain Neoplasm }\end{array}$ & $\begin{array}{l}\text { - Ferumoxytol } \\
\text { - } 3 \text { Tesla MRI } \\
\text { - Dynamic MRI }\end{array}$ & $\begin{array}{l}\text { NCT02857218 } \\
\text { NCT00103038 }\end{array}$ & Not applicable & 2005-still active & $\begin{array}{c}{[107]} \\
{[85]}\end{array}$ \\
\hline
\end{tabular}


Table 2. Cont.

\begin{tabular}{|c|c|c|c|c|c|}
\hline Pathology & Interventions & ClinicalTrials ID & Phase & Date (First-Last Posted) & Ref. \\
\hline $\begin{array}{l}\text { Bone Cancer } \\
\text { Chondrosarcoma } \\
\text { Ewing's Sarcoma }\end{array}$ & $\begin{array}{l}\text { - Feraheme } \\
\text { - MRI }\end{array}$ & NCT01336803 & Not applicable & 2011-still active & [87] \\
\hline $\begin{array}{l}\text { Glioblastoma } \\
\text { Malignant Primary and metastatic Brain } \\
\text { Neoplasm } \\
\text { Melanoma }\end{array}$ & $\begin{array}{l}\text { - Pembrolizumab } \\
\text { - Ferumoxytol } \\
\text { - MRI }\end{array}$ & NCT03347617 & Phase 2 & 2017-still active & [89] \\
\hline Adult Brain Glioblastoma & $\begin{array}{l}\text { - Gadolinium } \\
\text { - Ferumoxytol } \\
\text { - MRI }\end{array}$ & NCT00660543 & Not applicable & 2016-2017 & [90] \\
\hline Brain Neoplasms & Ferumoxytol & NCT00769093 & Phase 1 & 2008-2017 & [91] \\
\hline Myocardial Infarction & $\begin{array}{l}\text { - Ferumoxytol } \\
\text { - MRI }\end{array}$ & NCT01323296 & Not applicable & 2011-2014 & [92] \\
\hline Hereditary Hemorrhagic Telangiectasia & Feraheme MRI/MRA & NCT02977637 & Phase 1 & 2016-still active & [93] \\
\hline Diabetes Mellitus, Type 1 & $\begin{array}{l}\text { - Ferumoxytol } \\
\text { - MRI }\end{array}$ & NCT00585936 & Not applicable & 2008-2011 & [94] \\
\hline Type 1 Diabetes & $\begin{array}{l}\text { - Ferumoxytol } \\
\text { - MRI }\end{array}$ & NCT01521520 & Not applicable & 2012-still active & [95] \\
\hline Renal Transplant Rejection & $\begin{array}{l}\text { - Feraheme } \\
\text { - MRI-GE Healthcare } 3 \text { Tesla magnet }\end{array}$ & NCT02006108 & Not applicable & 2017-2018 & [96] \\
\hline Osteonecrosis & $\begin{array}{l}\text { - Ferumoxytol } \\
\text { - MRI }\end{array}$ & NCT02893293 & Phase 4 & 2015-still active & [97] \\
\hline CNS Neoplasm & $\begin{array}{l}\text { - Ferumoxytol } \\
\text { - Gadolinium } \\
\text { - MRI }\end{array}$ & NCT03270059 & Phase 2 & 2017-still active & [98] \\
\hline MS & $\begin{array}{l}\text { - Ferumoxytol } \\
\text { - MRI }\end{array}$ & NCT02511028 & Early Phase 1 & 2015-still active & [99] \\
\hline Epilepsy & $\begin{array}{l}\text { - Ferumoxytol injection after focal epileptic seizure } \\
\text { - MRI }\end{array}$ & NCT02084303 & Not applicable & 2014-2018 & [100] \\
\hline HIV Dementia & - Ferumoxytol & NCT01665846 & Phase 1 & 2012-2018 & [101] \\
\hline
\end{tabular}


Table 2. Cont

\begin{tabular}{|c|c|c|c|c|c|}
\hline Pathology & Interventions & ClinicalTrials ID & Phase & Date (First-Last Posted) & Ref. \\
\hline AIDS Dementia Complex & $\begin{array}{l}\text { - Ferumoxytol } \\
\text { - MRI }\end{array}$ & NCT02678767 & 2016-2017 & Phase 2 & [102] \\
\hline Peripheral Arterial Disease & $\begin{array}{l}\text { - Ferumoxytol } \\
\text { - MRI }\end{array}$ & NCT00707876 & Phase 2 & 2008-still active & [104] \\
\hline Cerebrovascular Disorders & Quantitative MRI & NCT03266848 & Not applicable & 2017-still active & [105] \\
\hline Infertility & MNP Sperm Separation for ICSI Cycles & NCT03666364 & Not applicable & $\begin{array}{l}\text { September 2018-still } \\
\text { active }\end{array}$ & [106] \\
\hline Acute Coronary Syndrome & Immunomagnetic reduction by MNPs & NCT02226523 & Not applicable & 2014-still active & [108] \\
\hline Lung Carcinoma & $\begin{array}{l}\text { - Pembrolizumab } \\
\text { - Ferumoxytol } \\
\text { - MRI }\end{array}$ & NCT03325166 & Phase 2 & 2017-still active & [109] \\
\hline Childhood Brain Neoplasm & $\begin{array}{l}\text { - Ferumoxytol } \\
\text { - MRI }\end{array}$ & NCT03234309 & Phase 2 & 2017-still active & [110] \\
\hline Nervous System Diseases & $\begin{array}{l}\text { - Ferumoxytol } \\
\text { - MRI }\end{array}$ & NCT00659776 & Phase 2 & 2008-2012 & [111] \\
\hline $\begin{array}{l}\text { Cardiac Transplant } \\
\text { Cardiac Sarcoid }\end{array}$ & $\begin{array}{l}\text { - Ferumoxytol } \\
\text { - MRI }\end{array}$ & NCT02319278 & $\begin{array}{l}\text { Phase } 2 \\
\text { Phase } 3\end{array}$ & 2014-2017 & [112] \\
\hline $\begin{array}{l}\text { Myocarditis } \\
\text { Pediatric Congenital Heart Disease }\end{array}$ & $\begin{array}{l}\text { - Ferumoxytol } \\
\text { - Gadofosveset }\end{array}$ & NCT02752191 & Phase 4 & 2016-still active & [113] \\
\hline Coronary Artery Disease & $\begin{array}{l}\text { - Ferumoxytol } \\
\text { - MRI }\end{array}$ & NCT02954510 & Phase 3 & 2016-still active & [114] \\
\hline $\begin{array}{l}\text { - Coronary Artery Disease } \\
\text { - Atherosclerosis }\end{array}$ & $\begin{array}{l}\text { - Stenting and micro } \\
\text {-infusion of GNPs } \\
\text { - Implantation of everolimus-eluting stent }\end{array}$ & NCT01436123 & Phase 1 & 2011-2015 & [115] \\
\hline Atherosclerosis & $\begin{array}{l}\text { - Ferumoxytol } \\
\text { - MRI scan }\end{array}$ & NCT01674257 & Not applicable & 2012-2013 & [116] \\
\hline Stroke & $\begin{array}{l}\text { - Radiation: 18f-Fluoride PET/CT } \\
\text { - Radiation: 18F-Flurodeoxyglucose PET/CT }\end{array}$ & & & & \\
\hline Ischemic Heart Disease & $\begin{array}{l}\text { Iron oxide-labeled mesenchymal stromal } \\
\text { MRI }\end{array}$ & NCT03651791 & Phase 1 & August 2018-still active & [117] \\
\hline
\end{tabular}




\subsection{Thermosensitive Nanomaterials for Disease Treatment}

Due to its characteristics, thermosensitive materials such as USPIOs, GNPs and lyso-thermosensitive liposomal formulations could be new therapeutic tools whose applicability is being demonstrated through various clinical trials (Table 3).

\subsubsection{Iron Deficiency Anemia in Patients with Chronic Kidney Disease}

Many formulations of USPIOs have already been approved by different countries for use in patients with IDA in CKD [118]. These formulations vary according to their coatings, which enhance the superparamagnetic properties of the nanoparticles in a different manner (Figure 3). The recommended treatment is intravenous (IV) iron administration for hemodialysis patients and either oral or IV iron for patients in CKD stages 1-5 who are anemic [119]. Currently, the efforts of researchers are focused on conducting comparative studies to find out which formulation is the best in terms of efficacy and side effects and which route of administration (IV or oral) is safer [120,121].

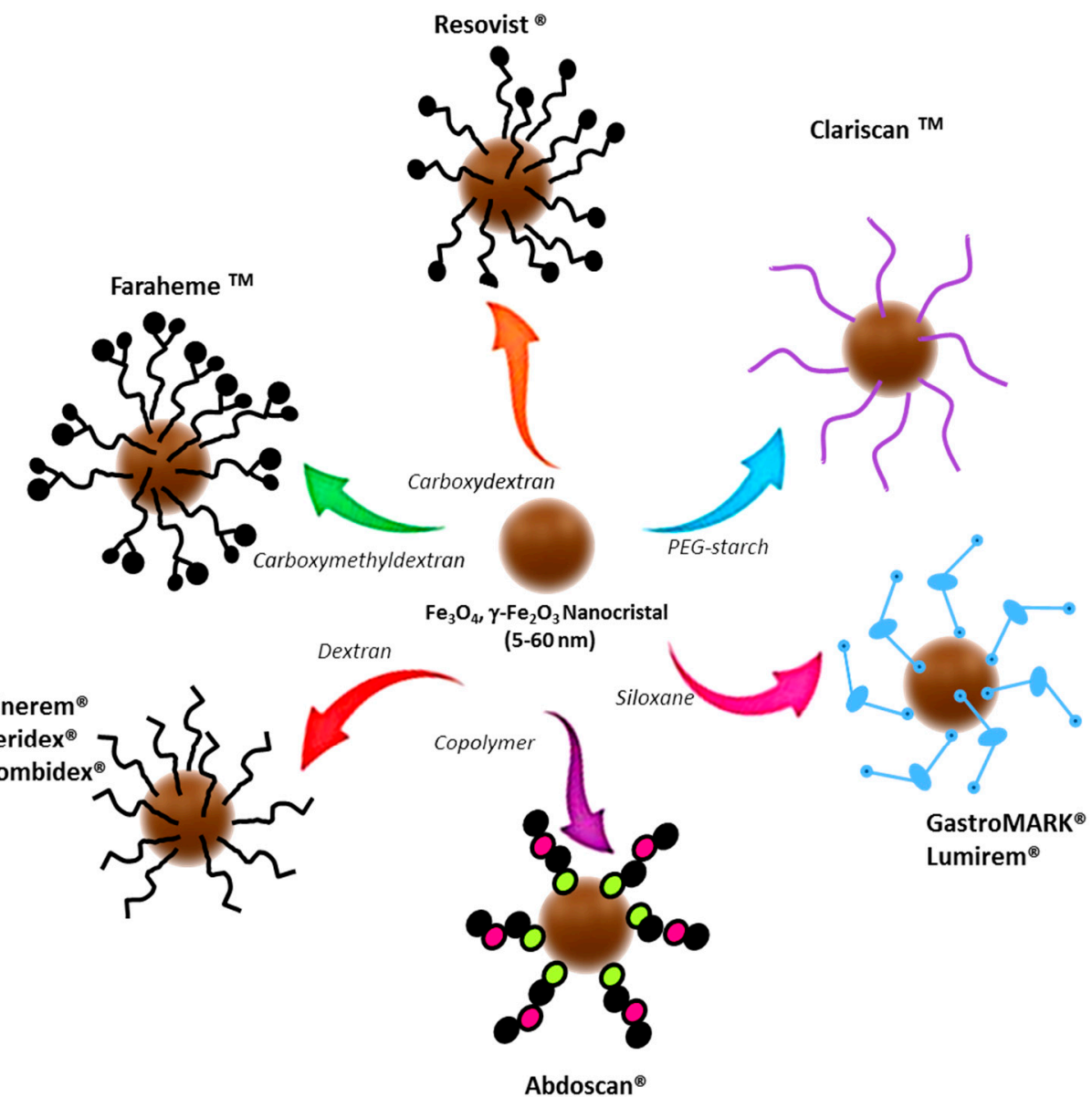

Figure 3. USPIOs clinically approved or in clinical trials.

A meta-analysis of small randomized trials reported the efficacy of oral compared to IV on hemoglobin response in CKD patients not on dialysis. In the short-term, one to three months, trials (five of the six trials reported in this meta-analysis) informed that the mean increase in hemoglobin with IV was $0.31 \mathrm{~g} / \mathrm{dL}$ compared to oral iron. However, in a longer trial (six months), the authors observed a mean decline in hemoglobin of $0.52 \mathrm{~g} / \mathrm{dL}$ associated with IV administration. The long-term safety of these modes of supplemental iron administration cannot be assessed because the duration of most clinical trials was short [118]. 
Recently, several clinical trials have been registered comparing ferumoxytol with other superparamagnetic iron formulations. Ferumoxytol (Feraheme ${ }^{\mathrm{TM}}$, AMAG Pharma Inc., Lexington, KY, USA) was approved for the treatment of IDA in adults with CKD in the United States and Canada (Feraheme injection) [122] together with the European Union and Switzerland (Rienso, withdrawn in 2015 for commercial reasons) [123]. Different to most other IV iron preparations, a complete cycle of ferumoxytol $(1.02 \mathrm{~g})$ requires only two IV injections of $510 \mathrm{mg}$ administered at a rate of up to $1 \mathrm{~mL} / \mathrm{s}(30 \mathrm{mg} / \mathrm{mL})$ between three and eight days apart. The two doses of ferumoxytol may have advantages for both patients and health professionals. In this context, the results of a clinical trial that examined rates of hypersensitivity reactions (HSRs) with IV iron formulations used to treat IDA have been published. In this multicenter, double-blind and randomized clinical trial, researchers compared the safety, and efficiency of ferumoxytol versus ferric carboxymaltose (FCM), aiming at the incidence of moderate-to-severe HSRs, including anaphylaxis, or moderate-to-severe hypotension as the primary end point and the incidence of moderate-to-severe HSRs, including anaphylaxis, serious cardiovascular events, and death as the secondary end point. Ferumoxytol was not inferior to FCM for both the primary and secondary composite safety end points, with an equivalent efficacy in increasing hemoglobin despite a lower dose. However, with FCM treatment severe hypophosphatemia was observed at higher rates [124].

Currently, a phase IV trial of repeated doses of ferumoxytol in comparison to iron sucrose for the treatment of IDA in patients with CKD on hemodialysis has been completed. The objectives of this study were to compare the efficacy and safety of repeat doses of IV ferumoxytol with IV iron sucrose for the treatment of IDA in subjects with hemodialysis-dependent CKD [125]. In 2014, the authors published their prelaminar results that indicate that ferumoxytol and iron sucrose show similar effectiveness and side effect rates [119].

\subsubsection{Cardiovascular Diseases}

In the field of cardiology, some clinical trials have been registered. Plasmonic nanophotothermal therapy is arousing great interest for atherosclerosis treatment. In fact, clinical trials are being carried out, with the objective of analyzing the feasibility of nanoburning to eliminate and reverse the plaque, especially in combination with stem cell technologies to achieve functional restoration of the vessel wall $[115,126]$. Moreover, a recent clinical trial has been initiated to evaluate the ability to trace iron oxide-labeled mesenchymal stromal cells (MSC) with MRI after NOGA-guided injection therapy into the myocardium for the treatment of ischemic heart disease [117]. Thus, the ability of USPIO labeled MSC injection to form new heart muscle cells and blood vessels in the myocardium, in order to improve myocardial blood flow and reduce patients' symptoms, will be analyzed.

\subsubsection{Diabetes}

A new drug based on the use of GNPs combined with peptide for the treatment of type I diabetes is in its first clinical trial passes [127]. Type 1 diabetes appears when the immune system (body's own white blood cells) destroys the beta cells that produce insulin in the pancreas. The objective is to develop a treatment that can slow or block this process by switching off the white blood cells causing the damage. In this clinical trial researchers investigate the safety and side effect of C19-A3 GNP, a peptide fragment related to insulin attached to GNPs, as a new therapeutic agent.

\subsubsection{Cancer}

In the field of oncology, perfect treatment is one that can be administrated under local anesthetic, can effectively abolish tumor cells, its bystander effect is limited only to surrounding tissues, can be repeatable, and adaptable to future discoveries such as anti-tumor molecular targeting. Magnetic thermoablation, that involves direct injection of MNPs into the tumor, may be able to fulfill these attributes. Magnetic thermoablation uses magnetic field to heat MNPs up to very high temperatures that destroy tumoral cells. In prostate cancer this approach has been investigated in two different 
ways (i) using MNP thermotherapy alone [128] and (ii) in combination with permanent seed brachytherapy [129]. In both trials, good tolerability and feasibility was shown using the first prototype of an AMF applicator [130]. This innovative approach requires specific tools for thermal monitoring, modeling techniques and quality control based on suitable imaging. Recently, an early phase 1 clinical trial was registered to investigate whether the MNPs remain in their injection site. This is essential to ensure the safety of this system. The consequences of their displacement can be fatal. Firstly, the MNPs could move away from the tumor cells resulting in a poor effectiveness of treatment as targeted cells will not be heated effectively. Secondly, the MNPs can reach sensitive structures around the prostate such as nerves controlling erections, bladder, sphincter muscle controlling urine flow, etc. In this case, the patient could develop serious side effects [131]. In this clinical trial, instead of heating the MNPs, the investigators will use special scans and then surgery, they will determine the exact localization of MNPs. Once determining its location in the injection site, the investigators will then be able to run another study using magnetic thermoablation to treat prostate cancer patients.

Lyso-thermosensitive liposomal is another system for antitumor targeted drug delivery that is

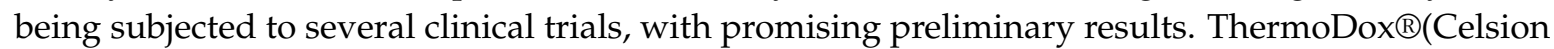
Corporation, Lawrenceville, NJ, USA) is a long-circulating Lyso-Thermosensitive Liposomal Doxorubicin (LTLD) approved for investigational use. ThermoDox®is a heat-activated drug delivery system supplied by IV infusion and facilitates targeted delivery of a cytotoxic drug (DOX) to tumors at temperatures exceeding $40{ }^{\circ} \mathrm{C}$ [132]. It was designed to be used in combination with heat-based treatments, such as microwave hyperthermia, high-intensity focused ultrasound (HIFU), or radiofrequency thermal ablation (RFA). The goal is to expand the effective treatment zone in order to capture micrometastases, which are most commonly responsible for post-treatment disease recurrence. In this context, TARDOX is a Phase 1 single center study of the administration of drugs directed by ultrasound in patients with incurable liver tumors. This proof of concept study was designed to prove the safety and feasibility of ThermoDox®unchained by mild hyperthermia induced by ultrasound focused on liver tumors $[133,134]$. This early phase 1 study demonstrated that the combination of LTLD and non-invasive ultrasound hyperthermia seemed to be clinically achievable, safe, and able to improve intratumoral drug delivery, providing targeted chemo-ablative response in human liver tumors that were intractable by standard chemotherapy [135]. A similar clinical trial is still ongoing for pediatric refractory solid tumors [136]. Other phase 2 and 3 clinical trials are investigating the safety, viability, and effectiveness of ThermoDox $®$ combined with standardized radiofrequency ablation for the treatment of both colon cancer liver metastasis [137] and hepatocellular carcinoma [138]; and microwave hyperthermia in the treatment of recurrent regional breast cancer $[139,140]$.

Table 3. Current clinical trials of thermosensitive nanomaterials for treatment of various diseases available on clinicaltrials.gov until November 2018.

\begin{tabular}{|c|c|c|c|c|c|}
\hline Pathology & Interventions & $\begin{array}{c}\text { ClinicalTrials } \\
\text { ID }\end{array}$ & Phase & $\begin{array}{c}\text { Date (First-Last } \\
\text { Posted) }\end{array}$ & Ref. \\
\hline CKD & $\begin{array}{l}\text { - Ferumoxytol } \\
\text { - MRA }\end{array}$ & NCT02997046 & Phase 4 & 2016-still active & [104] \\
\hline Ischemic Heart Disease & $\begin{array}{l}\text { - Iron oxide-labeled } \\
\text { mesenchymal stromal cells } \\
\text { - MRI }\end{array}$ & NCT03651791 & Phase 1 & $\begin{array}{c}\text { August } \\
\text { 2018-still active }\end{array}$ & [117] \\
\hline $\begin{array}{l}\text { IDA } \\
\text { Pediatric CKD }\end{array}$ & $\begin{array}{l}\text { - Ferumoxytol } \\
\text { - Oral Iron }\end{array}$ & NCT03619850 & Phase 3 & $\begin{array}{c}\text { August } \\
\text { 2018-still active }\end{array}$ & [120] \\
\hline $\begin{array}{l}\text { IDA } \\
\text { Pregnancy }\end{array}$ & Intravenous and Oral Iron & NCT03657433 & Phase 3 & September 2018 & [121] \\
\hline $\begin{array}{l}\text { IDA } \\
\text { CKD }\end{array}$ & $\begin{array}{l}\text { - Ferumoxytol } \\
\text { - Iron Sucrose }\end{array}$ & NCT01227616 & Phase 4 & 2010-2017 & [125] \\
\hline $\begin{array}{l}\text { - Stable Angina } \\
\text { - Heart Failure } \\
\text { - Atherosclerosis } \\
\text { - Multivessel Coronary } \\
\text { Artery Disease }\end{array}$ & $\begin{array}{l}\text { - GNPs } \\
\text { - Iron-bearing nanoparticles } \\
\text { - Stenting }\end{array}$ & NCT01270139 & Not applicable & 2012-2017 & [126] \\
\hline
\end{tabular}


Table 3. Cont.

\begin{tabular}{|c|c|c|c|c|c|}
\hline Pathology & Interventions & $\begin{array}{c}\text { ClinicalTrials } \\
\text { ID }\end{array}$ & Phase & $\begin{array}{l}\text { Date (First-Last } \\
\text { Posted) }\end{array}$ & Ref. \\
\hline Type 1 Diabetes & $\begin{array}{l}\text { - C19-A3 GNP (peptide } \\
\text { fragment related to insulin } \\
\text { attached to GNPs) }\end{array}$ & NCT02837094 & Phase 1 & 2016-still active & [127] \\
\hline Prostate Cancer & MNPs Injection & NCT02033447 & Early Phase 1 & 2013-2017 & [131] \\
\hline Liver Tumor & $\begin{array}{l}\text { - ThermoDox® } \\
\text { - Magnetic resonance high } \\
\text { intensity focused ultrasound }\end{array}$ & NCT02181075 & Phase 1 & 2014-2017 & [133] \\
\hline $\begin{array}{l}\text { Pediatric Cancer Solid } \\
\text { Tumors }\end{array}$ & $\begin{array}{l}\text { - ThermoDox® } \\
\text { - MRI } \\
\text { - High-intensity focused } \\
\text { ultrasound }\end{array}$ & NCT02536183 & Phase 1 & 2015-still active & [136] \\
\hline $\begin{array}{l}\text { Colon Cancer } \\
\text { Liver Metastasis }\end{array}$ & $\begin{array}{l}\text { - ThermoDox® } \\
\text { - Radiofrequency ablation }\end{array}$ & NCT01464593 & Phase 2 & 2011-2016 & [137] \\
\hline Hepatocellular Carcinoma & $\begin{array}{l}\text { - ThermoDox® } \\
\text { - Radiofrequency ablation }\end{array}$ & NCT02112656 & Phase 3 & 2014-still active & [138] \\
\hline Breast Cancer & $\begin{array}{l}\text { - ThermoDox }{ }^{\circledR} \\
\text { - Microwave hyperthermia }\end{array}$ & NCT00826085 & Phase 2 & 2009-2017 & [139] \\
\hline Breast Cancer & $\begin{array}{l}\text { - ThermoDox® } \\
\text { - MR-HIFU induced } \\
\text { hyperthermia } \\
\text { - Cyclophosphamide }\end{array}$ & NCT03749850 & Phase 1 & $\begin{array}{c}\text { November } \\
\text { 2018-still active }\end{array}$ & [140] \\
\hline $\begin{array}{l}\text { - IDA } \\
\text { - Non-dialysis-dependent } \\
\text { CKD }\end{array}$ & $\begin{array}{l}\text { - Ferumoxytol } \\
\text { - Oral Iron }\end{array}$ & NCT01155388 & Phase 3 & 2017-still active & [141] \\
\hline
\end{tabular}

\section{Conclusions}

Thermosensitive materials are very promising for biomedical treatments. However, much work remains to be done to solve its main limitations and facilitate its transfer to the clinic. In this context, one of the most important drawbacks of these nanoparticles is the cleareance and prolonged tissue retention which can cause toxicity. Moreover, some nanoparticles fail to overcome biological barriers end up accumulating in organs outside the target, such as the liver and spleen. This produces a non-specific distribution that negatively affects the diagnosis and treatment of tumors, since when generating hyperthermia, collateral damage in healthy organs cannot be avoided. Furthermore, for the use of MNPs combined with images of multiple modalities to be effective and simplify the non-invasive monitoring of treatments, a dose of MNPs particles necessary to produce the heating should be lowered so as not to cause saturation of the transverse relaxation time of MRI.

After having carried out an exhaustive search on the clinical trials that have been or are being developed on thermosensitive materials, we can conclude that (i) thermosensitive materials, particularly biosensors investigated for analytical and diagnostic applications (e.g., metal-based nanoparticles, thermosensitive polymers, thermoresponsive nanocomposites, and thermochromic dyes) have not reached the clinical trial phase yet. Indeed, all clinical trials consulted focus on the use of ferumoxytol as a current imaging test enhancer except for two newly started trials in September 2018. The first one uses MNPs in the treatment of infertility, and the second one investigates the safety of carbon black and graphene nanoparticles. None of the existing trials take advantage of the thermosensitive characteristics of nanoparticles. (ii) In the field of treatment, the thermosensitive characteristics of nanomaterials are being further exploited especially for the delivery of antitumor drugs. In this regard, ThermoDox®based on lysolipid thermally sensitive liposome technology to encapsulate DOX is the flagship drug. Currently, at the preclinical level, other liposomal formulations such as thermosensitive liposomal nanoparticle (TSLnp) loaded by GEM and paclitaxel (PLX) are under study for theranostic use in solid tumors. TSLnps significantly improved GEM and PLX delivery and enhanced its antitumor activity [50,142]. However, the formulation of Gd-TSLnp needs to be fully optimized to significantly enhance MRI contrast in tumor [50]. Moreover, multiple nano-liposomal 
systems have been successfully developed for drug delivery for non-tumoral pathologies, such as ocular diseases [143]. Other diseases like IDA, diabetes, and ischemic heart disease are also a target; pathologies are being treated by thermosensitive nanoparticles using USPIOs, fragment-related peptide to GNPs (C19-A3 GNP), and iron oxide-labeled mesenchymal stromal cells, respectively.

The discrepancy existing between the number of papers published on thermosensitive nanomaterials and the number of nanomaterials in clinical use could be due to several factors. On the one hand, there is the relative novelty of this area of research; the first manuscript related to thermosensitive nanoparticles published in PubMed is based on data from 2002, hence the need for a period of time for its validation through clinical trials before its clinical application. On the other hand, the complexity of thermo-nanocarriers prevents their use in delivering drugs. Indeed, reformulating most currently approved drugs, in nanosize form will provide a small improvement in performance that does not compensate for the efforts made by and the costs to pharmaceutical companies. This has already been observed in other areas of research in the field of nanomedicine [144,145]. However, we have no doubt that in the coming years there will be an explosion of clinical trials related to thermosensitive nanomaterials that will surely help to improve current treatments and above all will impact on patients' quality of life and life expectancy.

Author Contributions: All the authors contributed to the study design, drafting, and manuscript revision.

Funding: This research was supported by the Fundación Mutua Madrileña by the project FMM-AP16683-2017, Consejería de Salud Junta de Andalucía (PI-0089-2017), MINECO MAT 2016-78778-R, PCIN-2015-051 projects (Spain), European Regional Development Fund (ERDF) and from the Chair "Doctors Galera-Requena in cancer stem cell research".

Acknowledgments: S. Nardecchia acknowledges the European Union's Horizon 2020 research and innovation program under the Marie Skłodowska-Curie Grant Agreement (EF-ST)-H2020-MSCA-IF-2017 (Grant 795318).

Conflicts of Interest: The authors declare no conflict of interest.

\section{References}

1. Peppas, N.A.; Clegg, J.R. The challenge to improve the response of biomaterials to the physiological environment. Regen. Biomater. 2016, 3, 67-71. [CrossRef] [PubMed]

2. Lu, Y.; Aimetti, A.A.; Langer, R.; Gu, Z. Bioresponsive materials. Nat. Rev. Mater. 2016, 2, 16075. [CrossRef]

3. Sahle, F.F.; Gulfam, M.; Lowe, T.L. Design strategies for physical-stimuli-responsive programmable nanotherapeutics. Drug Discov. Today 2018, 23, 992-1006. [CrossRef] [PubMed]

4. Mohamed, S.M.; Veeranarayanan, S.; Maekawa, T.; Kumar, S.D. External stimulus responsive inorganic nanomaterials for cancer theranostics. Adv. Drug Deliv. 2018, in press. [CrossRef]

5. Sánchez-Moreno, P.; de Vicente, J.; Nardecchia, S.; Marchal, J.A.; Boulaiz, H. Thermo-sensitive nanomaterials: Recents advance in synthesis and biomedical applications. Nanomaterials 2018, 8, 935. [CrossRef] [PubMed]

6. Wust, P.; Hildebrandt, B.; Sreenivasa, G.; Rau, B.; Gellermann, J.; Riess, H.; Schlag, P.M. Hyperthermia in combined treatment of cancer. Lancet 2002, 3, 487-497. [CrossRef]

7. Datta, N.R.; Gómez Ordóñez, S.; Gaipl, U.S.; Paulides, M.M.; Crezee, H.; Gellermann, J.; Marder, D.; Puric, E.; Bodis, S. Local hyperthermia combined with radiotherapy and-/or chemotherapy: Recent advances and promises for the future. Cancer Treat. Rev. 2015, 41, 742-753. [CrossRef] [PubMed]

8. Lu, N.; Huang, P.; Fan, W.; Wang, Z.; Liu, Y.; Wang, S.; Zhang, G.; Hu, J.; Liu, W.; Niu, G.; et al. Tri-stimuli-responsive biodegradable theranostics for mild hyperthermia enhanced chemotherapy. Biomaterials 2017, 126, 39-48. [CrossRef] [PubMed]

9. Guisasola, E.; Baeza, A.; Asín, L.; de la Fuente, J.M.; Vallet-Regí, M. Heating at the nanoscale through drug-delivery devices: Fabrication and synergic effects in cancer treatment with nanoparticles. Small Methods 2018, 2, 1800007. [CrossRef]

10. Hayashi, K.; Ono, K.; Suzuki, H.; Sawada, M.; Moriya, M.; Sakamoto, W.; Yogo, T. High-frequency, magnetic-field-responsive drug release from magnetic nanoparticle/organic hybrid based on hyperthermic effect. ACS Appl. Mater. Interfaces 2010, 2, 1903-1911. [CrossRef] 
11. Cherukula, K.; Manickavasagam Lekshmi, K.M.; Uthaman, S.; Cho, K.; Cho, C.-S.; Park, I.-K. Multifunctional inorganic nanoparticles: Recent progress in thermal therapy and imaging. Nanomaterials 2016, 6, 76. [CrossRef] [PubMed]

12. Thorek, D.L.J.; Chen, A.K.; Czupryna, J.; Tsourkas, A. Superparamagnetic iron oxide nanoparticle probes for molecular imaging. Ann. Biomed. Eng. 2006, 34, 23-38. [CrossRef] [PubMed]

13. D'Acunto, M. Detection of intracellular gold nanoparticles: An overview. Materials 2018, 11, 882. [CrossRef] [PubMed]

14. Beik, J.; Abed, Z.; Ghoreishi, F.S.; Hosseini-Nami, S.; Mehrzadi, S.; Shakeri-Zadeh, A.; Kamrava, S.K. Nanotechnology in hyperthermia cancer therapy: From fundamental principles to advanced applications. J. Control. Release 2016, 235, 205-221. [CrossRef]

15. Jennings, L.E.; Long, N.J. 'Two is better than one'-probes for dual-modality molecular imaging. Chem. Commun. 2009, 3511-3524. [CrossRef]

16. Misri, R.; Meier, D.; Yung, A.C.; Kozlowski, P.; Häfeli, U.O. Development and evaluation of a dual-modality (MRI/SPECT) molecular imaging bioprobe. Nanomed. Nanotechnol. Biol. Med. 2012, 8, 1007-1016. [CrossRef]

17. Zhao, M.; Beauregard, D.A.; Louizou, L.; Davletov, B.; Brindle, K.M. Non-invasive detection of apoptosis using magnetic resonance imaging and a targeted contrast agent. Nat. Med. 2001, 7, 1241-1244. [CrossRef]

18. Seo, H.I.; Cheon, Y.A.; Chung, B.G. Graphene and thermo-responsive polymeric nanocomposites for therapeutic applications. Biomed. Eng. Lett. 2016, 6, 10-15. [CrossRef]

19. Kneidl, B.; Peller, M.; Winter, G.; Hossann, M. Thermosensitive liposomal drug delivery systems: State of the art review. Int. J. Nanomed. 2014, 9, 4387-4398. [CrossRef]

20. Ye, F.; Qin, J.; Toprak, M.S. Multifunctional core-shell nanoparticles: Superparamagnetic, mesoporous, and thermosensitive. J. Nanopart. Res. 2011, 13, 6157-6167. [CrossRef]

21. Elahi, N.; Kamali, M.; Baghersad, M.H. Recent biomedical applications of gold nanoparticles: A review. Talanta 2018, 184, 537-556. [CrossRef] [PubMed]

22. Colombo, M.; Carregal-Romero, S.; Casula, M.F.; Gutiérrez, L.; Morales, M.P.; Böhm, I.B.; Heverhagen, J.T.; Prosperi, D.; Parak, W.J. Biological applications of magnetic nanoparticles. Chem. Soc. Rev. 2012, 41, 4306-4334. [CrossRef] [PubMed]

23. Brazel, C.S. Magnetothermally-responsive nanomaterials: Combining magnetic nanostructures and thermally-sensitive polymers for triggered drug release. Pharm. Res. 2009, 26, 644-656. [CrossRef] [PubMed]

24. Ito, A.; Shinkai, M.; Honda, H.; Kobayashi, T. Medical application of functionalized magnetic nanoparticles. J. Biosci. Bioeng. 2005, 100, 1-11. [CrossRef]

25. Reyes-Ortega, F.; Delgado, A.V.; Schneider, E.K.; Checa Fernández, B.L.; Iglesias, G.R. Magnetic nanoparticles coated with a thermosensitive polymer with hyperthermia properties. Polymers 2018, 10, 10. [CrossRef]

26. Shen, L.; Li, B.; Qiao, Y. $\mathrm{Fe}_{3} \mathrm{O}_{4}$ nanoparticles in targeted drug/gene delivery systems. Materials 2018, 11,324 . [CrossRef] [PubMed]

27. Stafford, S.; Serrano Garcia, R.; Gun'ko, Y.K. Multimodal magnetic-plasmonic nanoparticles for biomedical applications. Appl. Sci. 2018, 8, 97. [CrossRef]

28. Lee, N.; Hyeon, T. Designed synthesis of uniformly sized iron oxide nanoparticles for efficient magnetic resonance imaging contrast agents. Chem. Soc. Rev. 2012, 41, 2575-2589. [CrossRef]

29. Sun, C.; Lee, J.S.H.; Zhang, M. Magnetic nanoparticles in MR imaging and drug delivery. Adv. Drug Deliv. Rev. 2008, 60, 1252-1265. [CrossRef]

30. Fan, W.; Yung, B.; Huang, P.; Chen, X. Nanotechnology for multimodal synergistic cancer therapy. Chem. Rev. 2017, 117, 13566-13638. [CrossRef]

31. Smith, B.R.; Gambhir, S.S. Nanomaterials for in vivo imaging. Chem. Rev. 2017, 117, 901-986. [CrossRef] [PubMed]

32. Fang, C.; Zhang, M. Multifunctional magnetic nanoparticles for medical imaging applications. J. Mater. Chem. 2009, 19, 6258-6266. [CrossRef] [PubMed]

33. Wahajuddin, S.A. Superparamagnetic iron oxide nanoparticles: Magnetic nanoplatforms as drug carriers. Int. J. Nanomed. 2012, 7, 3445-3471. [CrossRef]

34. Justin, C.; Philip, S.A.; Samrot, A.V. Synthesis and characterization of superparamagnetic iron-oxide nanoparticles (SPIONs) and utilization of SPIONs in X-ray imaging. Appl. Nanosci. 2017, 7, 463-475. [CrossRef] 
35. Mahmoudi, M.; Sant, S.; Wang, B.; Laurent, S.; Sen, T. Superparamagnetic iron oxide nanoparticles (SPIONs): Development, surface modification and applications in chemotherapy. Adv. Drug Deliv. Rev. 2011, 63, $24-46$. [CrossRef] [PubMed]

36. Kandasamy, G.; Sudame, A.; Luthra, T.; Saini, K.; Maity, D. Functionalized hydrophilic superparamagnetic iron oxide nanoparticles for magnetic fluid hyperthermia application in liver cancer treatment. ACS Omega 2018, 3, 3991-4005. [CrossRef] [PubMed]

37. Boulaiz, H.; Alvarez, P.J.; Ramirez, A.; Marchal, J.A.; Prados, J.; Rodríguez-Serrano, F.; Perán, M.; Melguizo, C.; Aranega, A. Nanomedicine: Application areas and development prospects. Int. J. Mol. Sci. 2011, 12, 3303-3321. [CrossRef]

38. Jain, P.K.; Huang, X.; El-Sayed, I.H.; El-Sayed, M.A. Review of some interesting surface Plasmon resonance-enhanced properties of noble metal nanoparticles and their applications to biosystems. Plasmonics 2007, 2, 107-118. [CrossRef]

39. Moreira, A.F.; Rodrigues, C.F.; Reis, C.A.; Costa, E.C.; Correia, I.J. Gold-core silica shell nanoparticles application in imaging and therapy: A review. Microporous Mesoporous Mater. 2018, 270, 168-179. [CrossRef]

40. Huang, P.; Lin, J.; Li, W.; Rong, P.; Wang, Z.; Wang, S.; Wang, X.; Sun, X.; Aronova, M.; Niu, G.; et al. Biodegradable gold nanovesicles with an ultrastrong plasmonic coupling effect for photoacoustic imaging and photothermal therapy. Angew. Chem. 2013, 52, 13958-13964. [CrossRef]

41. Abadeer, N.S.; Murphy, C.J. Recent progress in cancer thermal therapy using gold nanoparticles. J. Phys. Chem. C 2016, 120, 4691-4716. [CrossRef]

42. Huang, X.; Jain, P.K.; El-Sayed, I.H.; El-Sayed, M.A. Plasmonic phothermal therapy (PPTT) using gold nanoparticles. Lasers Med. Sci. 2008, 23, 217-228. [CrossRef] [PubMed]

43. Cha, C.; Shin, S.R.; Annabi, N.; Dokmeci, M.R.; Khademhosseini, A. Carbon-based nanomaterials: Multifunctional materials for biomedical engineering. ACS Nano 2013, 7, 2891-2897. [CrossRef]

44. Li, S.; Peng, Z.; Han, X.; Leblanc, R.M. Interactions between grapheme oxide and biomolecules from surface chemistry and spectroscopy. Recent Prog. Colloid Surf. Chem. Biol. Appl. ACS Symp. Ser. 2015, 1215, $43-64$. [CrossRef]

45. Liao, C.; Li, Y.; Tjong, S.C. Graphene nanomaterials: Synthesis, biocompatibility, and citotoxicity. Int. J. Mol. Sci. 2018, 19, 3564. [CrossRef] [PubMed]

46. Tabish, T.A.; Zhang, S.; Winyard, P.G. Developing the next generation of gaphene-based platforms for cancer therapeutics: The potential role of reactive oxygen species. Redox Biol. 2018, 15, 34-40. [CrossRef] [PubMed]

47. Koning, G.A.; Li, L.; ten Hagen, T.L.M. Thermosensitive liposomes for the delivery of cancer therapeutics. Ther. Deliv. 2010, 1, 707-711. [CrossRef] [PubMed]

48. Jain, A.; Jain, S.K. Stimuli-responsive smart liposomes in cancer targeting. Curr. Drug Targets 2018, 19, 259-270. [CrossRef] [PubMed]

49. Bulbake, U.; Doppalapudi, S.; Kommineni, N.; Khan, W. Liposomal formulations in clinical use: An update review. Pharmaceutics 2017, 9, 12. [CrossRef] [PubMed]

50. Affram, K.; Udofot, O.; Singh, M.; Krishnan, S.; Reams, R.; Rosenberg, J.; Agyare, E. Smart thermosensitive liposomes for effective solid tumor therapy and in vivo imaging. PLoS ONE 2017, 12, e0185116. [CrossRef]

51. Dicheva, B.M.; ten Hagen, T.L.M.; Seynhaeve, A.L.B.; Amin, M.; Eggermont, A.M.M.; Koning, G.A. Enhanced specificity and drug delivery in tumors by cRGD-anchiring thermosensitive liposomes. Pharm. Res. 2015, 32, 3862-3876. [CrossRef] [PubMed]

52. Needham, D.; Anyarambhatla, G.; Kong, G.; Dewhirst, M.W. A new temperature-sensitive liposome for use with mild hyperthermia: Characterization and testing in a human tumor xenograft model. Cancer Res. 2000, 60, 1197-1201. [PubMed]

53. Dou, Y.; Hynynen, K.; Allen, C. To heat or not to heat: Challenges with clinical translation of thermosensitive liposomes. J. Control. Release 2017, 249, 63-73. [CrossRef] [PubMed]

54. Lindner, L.H.; Eichhorn, M.E.; Eibl, H.; Teichert, N.; Schmitt-Sody, M.; Issels, R.D.; Dellian, M. Novel Temperature-Sensitive Liposomes with Prolonged Circulation Time. Clin. Cancer Res. 2004, 10, 2168-2178. [CrossRef] [PubMed]

55. Limmer, S.; Hahn, J.; Schmidt, R.; Wachholz, K.; Zengerle, A.; Lechner, K.; Eibl, H.; Issels, R.D.; Hossann, M.; Lindner, L.H. Gemcitabine treatment of rat soft tissue sarcoma with phosphatidyldiglycerol-based thermosensitive liposomes. Pharm. Res. 2014, 31, 2276-2286. [CrossRef] [PubMed] 
56. Dou, Y.N.; Zheng, J.; Foltz, R.; Weersink, R.; Chaudary, N.; Jaffray, D.A.; Allen, C. Heat-activated thermosensitive liposomal cisplatin (HTLC) results in effective growth delay of cervical carcinoma in mice. J. Control. Release 2014, 178, 69-78. [CrossRef] [PubMed]

57. May, J.P.; Ernsting, M.J.; Undzys, E.; Li, S.D. Thermosensitive liposomes for the delivery of gemcitabine and oxaliplatin to tumors. Mol. Pharm. 2013, 10, 4499-4508. [CrossRef] [PubMed]

58. Sneider, A.; VanDyke, D.; Paliwal, S.; Rai, P. Remotely triggered nano-theranostics for cancer applications. Nanotheranostics 2017, 1, 1-22. [CrossRef] [PubMed]

59. Xing, H.; Hwang, K.; Lu, Y. Recent developments of liposomes as nanocarriers for theranostic applications. Theranostics 2016, 6, 1336-1352. [CrossRef] [PubMed]

60. Du, B.; Han, S.; Li, H.; Zhao, F.; Su, X.; Cao, X.; Zhang, Z. Multi-functional liposomes showing radiofrequency-triggered release and magnetic resonance imaging for tumor multi-mechanism therapy. Nanoscale 2015, 7, 5411-5426. [CrossRef] [PubMed]

61. Garello, F.; Terreno, E. Sonosensitive MRI nanosystems as cancer theranostics: A recent update. Front. Chem. 2018, 6, 157. [CrossRef] [PubMed]

62. Rizzitelli, S.; Giustetto, P.; Faletto, D.; Delli Castelli, D.; Aime, S.; Terreno, E. The release of Doxorubicin from liposomes monitored by MRI and triggered by a combination of US stimuli led to a complete tumor regression in a breast cancer mouse model. J. Control. Release 2016, 230, 57-63. [CrossRef] [PubMed]

63. Zhao, P.; Zheng, M.; Luo, Z.; Gong, P.; Gao, G.; Sheng, Z.; Zheng, C.; Ma, Y.; Cai, L. NIR-driven smart theranostic nanomedicine for on-demand drug release and synergistic antitumour therapy. Sci. Rep. 2015, 5, 14258. [CrossRef]

64. Meng, L.; Deng, Z.; Niu, L.; Li, F.; Yan, F.; Wu, J.; Cai, F.; Zheng, H. A disposable microfluidic device for controlled drug release from thermal-sensitive liposomes by high intensity focused ultrasound. Theranostics 2015, 5, 1203-1213. [CrossRef] [PubMed]

65. Banno, B.; Ickenstein, L.M.; Chiu, G.N.C.; Bally, M.B.; Thewalt, J.; Brief, E.; Wasan, E.K. The functional roles of poly(ethylene glycol)-lipid and lysolipid in the drug retention and release from lysolipid-containing thermosensitive liposomes in vitro and in vivo. J. Pharm. Sci. 2010, 99, 2295-2308. [CrossRef] [PubMed]

66. Kokuryo, D.; Nakashima, S.; Ozaki, F.; Yuba, E.; Chuang, K.-H.; Aoshima, S.; Ishizaka, Y.; Saga, T.; Kono, K.; Aoki, I. Evaluation of thermo-triggered drug release in intramuscular-transplanted tumors using thermosensitive polymer-modified liposomes and MRI. Nanomed. Nanotechnol. Biol. Med. 2015, 11, 229-238. [CrossRef]

67. Shemesh, C.S.; Hardy, C.W.; Yu, D.S.; Fernandez, B.; Zhang, H. Indocyanine green loaded liposome nanocarriers for photodynamic therapy using human triple negative breast cancer cells. Photodiagn. Photodyn. Ther. 2014, 11, 193-203. [CrossRef]

68. Sun, Q.; You, Q.; Wang, J.; Liu, L.; Wang, Y.; Song, Y.; Cheng, Y.; Wang, S.; Tan, F.; Li, N. Theranostic nanoplatform: Triple-modal imaging-guided synergistic cancer therapy based on liposome-conjugated mesoporous silica nanoparticles. ACS Appl. Mater. Interfaces 2018, 10, 1963-1975. [CrossRef]

69. Andrews, J. The Role of Eicosanoids in the Cardiovascular Actions of Inhaled Nanoparticles (ECOARM); ClinicalTrials.gov Identifier: NCT03659864; Centre for Cardiovascular Science: Edinburgh, UK, 2018.

70. Wang, Y.X.; Idee, J.M. A comprehensive literatures update of clinical researches of superparamagnetic resonance iron oxide nanoparticles for magnetic resonance imaging. Quant. Imaging Med. Surg. 2017, 7, 88-122. [CrossRef]

71. Bashir, M.R.; Batti, L.; Marin, D.; Nelson, R.C. Emerging applications for ferumoxytol as a contrast agent in MRI. J. Magn. Reson. Imaging 2015, 41, 884-898. [CrossRef]

72. Hamilton, B.E.; Nesbit, G.M.; Dosa, E.; Gahramanov, S.; Rooney, B.; Nesbit, E.G.; Raines, J.; Neuwelt, E.A. Comparative analysis of ferumoxytol and gadoteridol enhancement using T1- and T2-weighted MRI in neuroimaging. Am. J. Roentgenol. 2011, 197, 981-988. [CrossRef] [PubMed]

73. Toth, G.B.; Varallyay, C.G.; Horvath, A.; Bashir, M.R.; Choyke, P.L.; Daldrup-Link, H.E.; Dosa, E.; Finn, J.P.; Gahramanov, S.; Harisinghani, M.; et al. Current and potential imaging applications of ferumoxytol for magnetic resonance imaging. Kidney Int. 2017, 92, 47-66. [CrossRef] [PubMed]

74. Neuwelt, E. Ferumoxytol-and Gadolinium-Labeled MRI in Measuring Tumors before or after Treatment in Patients with Primary or Metastatic Brain; ClinicalTrials.gov Identifier: NCT00659126; OHSU Knight Cancer Institute: Portland, OR, USA, 2008. 
75. Fuller, C. Ferumoxytol-Iron Oxide Nanoparticle Magnetic Resonance Dynamic Contrast Enhanced MRI; ClinicalTrials.gov Identifier: NCT01895829; University of Texas MD Anderson Cancer Center: Houston, TX, USA, 2013.

76. Ipsen. MM-398 (Nanoliposomal Irinotecan, NaI-IRI) to Determine Tumor Drug Levels and to Evaluate the Feasibility of Ferumoxytol Magnetic Resonance Imaging to Measure Tumor Associated Macrophages and to Predict Patient Response to Treatment; ClinicalTrials.gov Identifier: NCT01770353; Mayo Clinic and HonorHealth: Scottsdale, AZ, USA, 2013.

77. Guimaraes, A. Ferumoxytol-Enhanced MRI in Imaging Lymph Nodes in Patients with Locally Advanced Rectal Cancer; ClinicalTrials.gov Identifier: NCT03280277; OHSU Knight Cancer Institute: Portland, OR, USA, 2017.

78. Choi, H. Clinical and Technical Feasibility of a Ultrasuperparamagnetic Nanoparticle Iron Oxide (USPIO)-Enhanced Magnetic Resonance Lymph; ClinicalTrials.gov Identifier: NCT01815333; University of Texas MD Anderson Cancer Center: Houston, TX, USA, 2013.

79. Choyke, P.L. Ferumoxytol Enhanced MRI for the Detection of Lymph Node Involvement in Prostate Cancer; ClinicalTrials.gov Identifier: NCT01296139; National Cancer Institute (NCI): Rockville, MD, USA, 2011.

80. Turkbey, I.B. Study of Ferumoxytol Enhanced MRI for Detecting Lymph Node Metastases in Prostate, Bladder, and Kidney Cancers; ClinicalTrials.gov Identifier: NCT02141490; National Cancer Institute (NCI): Rockville, MD, USA, 2014.

81. Harisinghani, M. Magnetic Resonance Imaging of Lymph Nodes Using Ferumoxytol in Patients with Primary Prostate or Breast Cancer; ClinicalTrials.gov Identifier: NCT00087347; Massachusetts General Hospital Cancer Center: Boston, MA, USA, 2004.

82. Neuwelt, E. DSC-MRI with Ferumoxytol and DCE-MRI with Gadolinium in Imaging Vascular Properties in Younger Patients with Brain Tumors; ClinicalTrials.gov Identifier: NCT00978562; OHSU Knight Cancer Institute: Portland, OR, USA, 2009.

83. Iv, M. Using Ferumoxytol-Enhanced MRI to Measure Inflammation in Patients with Brain Tumors or Other Conditions of the CNS; ClinicalTrials.gov Identifier: NCT02452216; Stanford University Hospitals and Clinics: Stanford, CA, USA, 2015.

84. Iv, M. In Vivo Characterization of Macrophages in Pediatric Patients with Malignant Brain Tumors Using Ferumoxytol-Enhanced MRI; ClinicalTrials.gov Identifier: NCT03179449; Stanford University Hospitals and Clinics: Stanford, CA, USA, 2017.

85. Neuwelt, E. Ferumoxytol in Improving MR Imaging in Patients with High-Grade Brain Tumors or Cerebral Metastases; ClinicalTrials.gov Identifier: NCT00103038; OHSU Knight Cancer Institute: Portland, OR, USA, 2005.

86. Seyfer, P.; Pagenstecher, A.; Mandic, R.; Klose, K.J.; Heverhagen, J.T. Cancer and inflammation: Differentiation by USPIO-enhanced MR imaging. J. Magn. Reson. Imaging 2014, 39, 665-672. [CrossRef]

87. Daldrup-Link, H.E.; Marina, N. Differentiation of Bone Sarcomas and Osteomyelitis with Ferumoxytol-Enhanced MRI; ClinicalTrials.gov Identifier: NCT01336803; Stanford University School of Medicine: Stanford, CA, USA, 2011.

88. Brandsma, D.; Stalpers, L.; Taal, W.; Sminia, P.; van den Bent, M.J. Clinical features, mechanisms, and management of pseudoprogression in malignant gliomas. Lancet Oncol. 2008, 9, 453-461. [CrossRef]

89. Neuwelt, E. Ferumoxytol MRI in Assessing Response to Pembrolizumab in Patients with Brain Tumors from Melanoma and Glioblastoma; ClinicalTrials.gov Identifier: NCT03347617; OHSU Knight Cancer Institute: Portland, OR, USA, 2017.

90. Neuwelt, E. MRI Study with Ferumoxytol in Assessing Early Response in Patients with Glioblastoma Multiforme Receiving Temozolomide and Radiation Therapy; ClinicalTrials.gov Identifier: NCT00660543; OHSU Knight Cancer Institute: Portland, OR, USA, 2008.

91. Neuwelt, E. Assessing Dynamic Magnetic Resonance (MR) Imaging in Patients with Recurrent High Grade Glioma Receiving Chemotherapy; ClinicalTrials.gov Identifier: NCT00769093; OHSU Knight Cancer Institute: Portland, OR, USA, 2008.

92. Newby, D.E. Ferumoxytol for Magnetic Resonance Imaging of Myocardial; ClinicalTrials.gov Identifier: NCT01323296; Royal Infirmary of Edinburgh: Edinburgh, UK, 2011.

93. Sigalov, V. MRA with Feraheme in HHT; ClinicalTrials.gov Identifier: NCT02977637; University of California: California, CA, USA, 2016. 
94. Jackson, R.A. Imaging Inflammation in Autoimmune Diabetes; ClinicalTrials.gov Identifier: NCT00585936; Joslin Diabetes Cente: Boston, MA, USA, 2008.

95. Gaglia, J. Imaging of Type 1 Diabetes Progression; ClinicalTrials.gov Identifier: NCT01521520; Massachusetts General Hospital: Boston, MA, USA, 2012.

96. Daldrup-Link, H.E. Imaging Kidney Transplant Rejection Using Ferumoxytol-Enhanced Magnetic Resonance; ClinicalTrials.gov Identifier: NCT02006108; Lucile Packard Children's Hospital: Palo Alto, CA, USA, 2013.

97. Daldrup-Link, H.E. Imaging of Osteonecrosis with Ferumoxytol-Enhanced MRI; ClinicalTrials.gov Identifier: NCT02893293; Lucile Packard Children's Hospital: Palo Alto, CA, USA, 2016.

98. Neuwelt, E. Gadolinium and Ferumoxytol MRI in Diagnosing with Abnormalities in the Central Nervous System; ClinicalTrials.gov Identifier: NCT03270059; OHSU Knight Cancer Institute: Portland, OR, USA, 2017.

99. Reich, D.S. In Vivo Characterization of Inflammation with Ferumoxytol, an Ultrasmall Superparamagnetic Iron Oxide Nanoparticle, on 7 Tesla Magnetic Resonance Imaging; ClinicalTrials.gov Identifier: NCT02511028; National Institutes of Health Clinical Center: Bethesda, MD, USA, 2015.

100. Jobst, B.C. Imaging Neuroinflammation in Epilepsy with Ferumoxytol MRI (IRONMAN); ClinicalTrials.gov Identifier: NCT02084303; Dartmouth-Hitchcock Medical Center: Lebanon, NH, USA, 2014.

101. Nakamoto, B.K. Ferumoxytol-Enhanced Brain MRI in HIV-Associated Neurocognitive Disorders; ClinicalTrials.gov Identifier: NCT01665846; Hawaii Center for AIDS: Honolulu, HI, USA, 2012.

102. Nakamoto, B.K. Ferumoxytol-Enhanced Imaging and Mapping in neuroAIDS; ClinicalTrials.gov Identifier: NCT02678767; Hawaii Center for AIDS: Honolulu, HI, USA, 2016.

103. Stoumpos, S. Ferumoxytol Enhanced Magnetic Resonance Angiography in Chronic Kidney Disease (FeMRA in CKD); ClinicalTrials.gov Identifier: NCT02997046; NHS Greater Glasgow and Clyde: Glasgow, UK, 2016.

104. Strauss, W. Magnetic Resonance Angiography for Peripheral Arterial Disease (PAD); ClinicalTrials.gov Identifier: NCT00707876; AMAG Pharmaceuticals, Inc.: Waltham, MA, USA, 2008.

105. Sridhar, S. Quantitative Non-Invasive Brain Imaging Using QUTE-CE MRI; ClinicalTrials.gov Identifier: NCT0326684; Massachusetts General Hospital: Boston, MA, USA, 2017.

106. Fawzy, M. Magnetic Nanoparticle Sperm Separation for Teratozoospermia Male and Women Older than 35 Years; ClinicalTrials.gov Identifier: NCT03666364; Ibn Sina Hospital (EGY): Giza, Egypt, 2018.

107. Guimaraes, A. Ferumoxytol-Enhanced MRI in Imaging Lymph Nodes in Patients with Stage IIB-IIC Esophageal Cancer; ClinicalTrials.gov Identifier: NCT02857218; OHSU Knight Cancer Institute: Portland, OR, USA, 2016.

108. Wu, Y.-W. Magnetic Nanoparticles System in Acute Coronary Syndrome; ClinicalTrials.gov Identifier: NCT02226523; Far Eastern Memorial Hospital (TWN): New Taipei City, Taiwan, 2014.

109. Ambady, P. Pembrolizumab and Magnetic Resonance Imaging with Ferumoxytol in Treating Patients with Non-Small Cell Lung Cancer and Brain; ClinicalTrials.gov Identifier: NCT03325166; OHSU Knight Cancer Institute: Portland, OR, USA, 2017.

110. Neuwelt, E. Ferumoxytol in Magnetic Resonance Imaging of Pediatric Patients with Brain Tumors; ClinicalTrials.gov Identifier: NCT03234309; OHSU Knight Cancer Institute: Portland, OR, USA, 2017.

111. Neuwelt, E. MR, Histologic and EM Imaging of Intravenous Ferumoxytol in Central Nervous System (CNS) Inflammation; ClinicalTrials.gov Identifier: NCT00659776; OHSU Knight Cancer Institute: Portland, OR, USA, 2008.

112. Stirrat, C. Detection of Cellular Inflammation with Ferumoxytol in the HEART (DECIFER); ClinicalTrials.gov Identifier: NCT02319278; Royal Infirmary of Edinburgh: Edinburgh, UK, 2014.

113. Finn, P. Feraheme as an MRI Contrast Agent for Pediatric Congenital Heart Disease; ClinicalTrials.gov Identifier: NCT02752191; UCLA Medical Center: Los Angele, CA, USA, 2016.

114. Siedlecki, A.M. Ferumoxytol for Magnetic Resonance Imaging in Patients with Severe Kidney Disease; ClinicalTrials.gov Identifier: NCT02954510; Brigham and Women's Hospital: Boston, MA, USA, 2016.

115. Kharlamov, A. Plasmonic Photothermal and Stem Cell Therapy of Atherosclerosis Versus Stenting (NANOM PCI); ClinicalTrials.gov Identifier: NCT01436123; De Haar Research Foundation (NLD): Utrecht, The Netherlands, 2011.

116. Newby, D.E. Metabolic Imaging in Carotid Atherosclerosis (MICA); ClinicalTrials.gov Identifier: NCT01674257; University of Edinburgh: Edinburgh, UK, 2012.

117. Kastrup, J. In Vivo Tracking of USPIO Labeled MSC in the Heart (USPIO-MSC); ClinicalTrials.gov Identifier: NCT03651791; Rigshospitalet (DNK): København, Danmark, 2018. 
118. Agarwal, R. Iron deficiency anemia in chronic kidney disease: Uncertainties and cautions. Hemodial. Int. 2017, 21 (Suppl. 1), S78-S82. [CrossRef] [PubMed]

119. Macdougall, I.C.; Strauss, W.E.; McLaughlin, J.; Li, Z.; Dellanna, F.; Hertel, J. A randomized comparison of ferumoxytol and iron sucrose for treating iron deficiency anemia in patients with CKD. Clin. J. Am. Soc. Nephrol. CJASN 2014, 9, 705-712. [CrossRef] [PubMed]

120. Duncan, M. A Study to Evaluate the Safety (Compared to Iron Sucrose), Efficacy and Pharmacokinetics of Ferumoxytol for the Treatment of Iron Deficiency Anemia (IDA) in Pediatric Subjects with Chronic Kidney Disease (CKD); ClinicalTrials.gov Identifier: NCT03619850; AMAG Pharmaceuticals, Inc.: Waltham, MA, USA, 2018.

121. Hill, M. Intravenous Infusions of Ferumoxytol Compared to Oral Ferrous Sulfate for the Treatment of Anemia in Pregnancy; ClinicalTrials.gov Identifier: NCT03657433; University of Arizona: Tucson, AZ, USA, 2018.

122. Lu, M.; Cohen, M.H.; Rieves, D.; Pazdur, R. FDA report: Ferumoxytol for intravenous iron therapy in adult patients with chronic kidney disease. Am. J. Hematol. 2010, 85, 315-319. [CrossRef]

123. European Medicines Agency. Available online: https://www.ema.europa.eu/en/medicines/human/EPAR/ rienso (accessed on 30 November 2018).

124. Adkinson, N.F.; Strauss, W.E.; Macdougall, I.C.; Bernard, K.E.; Auerbach, M.; Kaper, R.F.; Chertow, G.M.; Krop, J.S. Comparative safety of intravenous ferumoxytol versus ferric carboxymaltose in iron deficiency anemia: A randomized trial. Am. J. Hematol. 2018, 93, 683-690. [CrossRef] [PubMed]

125. A Phase IV Trial of Repeated Doses of Ferumoxytol Compared to Iron Sucrose for the Treatment of Iron Deficiency Anemia in Patients with Chronic Kidney Disease on Hemodialysis (FACT); ClinicalTrials.gov Identifier: NCT01227616; AMAG Pharmaceuticals, Inc.: Waltham, MA, USA, 2010.

126. Gabinsky, J.; Kovtun, O.; Kharlamov, A. Plasmonic Nanophotothermal Therapy of Atherosclerosis (NANOM-FIM); ClinicalTrials.gov Identifier: NCT01270139; De Haar Research Foundation (NLD): Utrecht, The Netherlands, 2011.

127. Pell, J.C.; Stenson, R. Enhanced Epidermal Antigen Specific Immunotherapy trial-1 (EE-ASI-1); ClinicalTrials.gov Identifier: NCT02837094; Cardiff University: Cardiff, UK, 2016.

128. Johannsen, M.; Gneveckow, U.; Eckelt, L.; Feussner, A.; Waldöfner, N.; Scholz, R.; Deger, S.; Wust, P.; Loening, S.A.; Jordan, A. Clinical hyperthermia of prostate cancer using magnetic nanoparticles: Presentation of a new interstitial technique. Int. J. Hyperth. 2005, 21, 637-647. [CrossRef]

129. Wust, P.; Gneveckow, U.; Johannsen, M.; Bohmer, D.; Henkel, T.; Kahmann, F.; Sehouli, J.; Felix, R.; Ricke, J.; Jordan, A. Magnetic nanoparticles for interstitial thermotherapy-feasibility, tolerance and achieved temperatures. Int. J. Hyperth. 2006, 22, 673-685. [CrossRef]

130. Johannsen, M.; Thiesen, B.; Wust, P.; Jordan, A. Magnetic nanoparticle hyperthermia for prostate cancer. Int. J. Hyperth. 2010, 26, 790-795. [CrossRef] [PubMed]

131. Ahmed, H. Magnetic Nanoparticle Thermoablation-Retention and Maintenance in the Prostate: A Phase 0 Study in Men (MAGNABLATE I); ClinicalTrials.gov Identifier: NCT02033447; University College London Hospital: London, UK, 2014.

132. Swenson, C.E.; Haemmerich, D.; Maul, D.H.; Knox, B.; Ehrhart, N.; Reed, R.A. Increased duration of heating boosts local drug deposition during radiofrequency ablation in combination with thermally sensitive liposomes (ThermoDox) in a porcine model. PLoS ONE 2015, 10, e0139752. [CrossRef] [PubMed]

133. Middleton, M. Targeted Chemotherapy Using Focused Ultrasound for Liver Tumours (TARDOX); ClinicalTrials.gov Identifier: NCT02181075; Oxford University Hospitals NHS Trust: Oxford, UK, 2014.

134. Lyon, P.C.; Griffiths, L.F.; Lee, J.; Chung, D.; Carlisle, R.; Wu, F.; Middleton, M.R.; Gleeson, F.V.; Coussios, C.C. Clinical trial protocol for TARDOX: A phase I study to investigate the feasibility of targeted release of lyso-thermosensitive liposomal doxorubicin (ThermoDox®) using focused ultrasound in patients with liver tumours. J. Ther. Ultrasound 2017, 5, 28. [CrossRef]

135. Lyon, P.C.; Gray, M.D.; Mannaris, C.; Folkes, L.K.; Stratford, M.; Campo, L.; Chung, D.Y.F.; Scott, S.; Anderson, M.; Goldin, R.; et al. Safety and feasibility of ultrasound-triggered targeted drug delivery of doxorubicin from thermosensitive liposomes in liver tumours (TARDOX): A single-centre, open-label, phase 1 trial. Lancet Oncol. 2018. [CrossRef]

136. Stern, E. A Phase I Study of Lyso-Thermosensitive Liposomal Doxorubicin and MR-HIFU for Pediatric Refractory Solid Tumors; ClinicalTrials.gov Identifier: NCT02536183; Children's National Medical Center: Washington, DC, USA, 2015. 
137. Borys, N. Phase II Study of Thermodox as Adjuvant Therapy with Thermal Ablation (RFA) in Treatment of Metastatic Colorectal Cancer (mCRC); ClinicalTrials.gov Identifier: NCT01464593; Celsion: Lawrenceville, NJ, USA, 2011.

138. Lencioni, R.; Ping Poon, R.T.; Hua, C.M. Study of Thermodox with Standardized Radiofrequency Ablation (RFA) for Treatment of Hepatocellular Carcinoma (HCC) (OPTIMA); ClinicalTrials.gov Identifier: NCT02112656; Celsion: Lawrenceville, NJ, USA, 2014.

139. Borys, N. Phase $1 / 2$ Study of Thermodox with Approved Hyperthermia in Treatment of Breast Cancer Recurrence at the Chest Wall (DIGNITY); ClinicalTrials.gov Identifier: NCT00826085; Celsion: Lawrenceville, NJ, USA, 2009.

140. de Maar, J.S.; Suelmann, B.B.M. Image-Guided Targeted Doxorubicin Delivery with Hyperthermia To Optimize Loco-Regional Control in Breast Cancer (i-GO); ClinicalTrials.gov Identifier: NCT03749850; UMC Utrecht (NLD): Utrecht, The Netherlands, 2018.

141. A Trial of Ferumoxytol for the Treatment of Iron Deficiency Anemia in Pediatric Participants with Nondialysis-Dependent Chronic Kidney Disease; ClinicalTrials.gov Identifier: NCT01155388; AMAG Pharmaceuticals, Inc.: Waltham, MA, USA, 2010.

142. Mahajan, M.; Utreja, P.; Jain, S.K. Paclitaxel loaded nanoliposomes in thermosensitive hydrogel: A dual approach for sustained and localized delivery. Anti-Cancer Agents Med. Chem. 2016, 16, 365-376. [CrossRef]

143. Agrahari, V.; Patel, S.P.; Dhall, N.; Aulgur, Z.; Thukral, S.; Yang, X.; Conley, R.; Mitra, A.K. Nanoparticles in thermosensitive gel based composite nanosystem for ocular diseases. Drug Deliv. Transl. Res. 2018, 8, 422-435. [CrossRef] [PubMed]

144. Sanchez-Moreno, P.; Ortega-Vinuesa, J.L.; Peula-Garcia, J.M.; Marchal, J.A.; Boulaiz, H. Smart drug-delivery systems for cancer nanotherapy. Curr. Drug Targets 2018, 19, 339-359. [CrossRef] [PubMed]

145. Venditto, V.J.; Szoka, F.C., Jr. Cancer nanomedicines: So many papers and so few drugs! Adv. Drug Deliv. Rev. 2013, 65, 80-88. [CrossRef]

(C) 2019 by the authors. Licensee MDPI, Basel, Switzerland. This article is an open access article distributed under the terms and conditions of the Creative Commons Attribution (CC BY) license (http://creativecommons.org/licenses/by/4.0/). 